\title{
Numerical and Experimental Aerodynamic Characterization of the HEXAFLY-INT Hypersonic Glider
}

\author{
Marco Marini ${ }^{1}$, Giuseppe Pezzella ${ }^{2}$, Antonio Schettino ${ }^{3}$, Sara Di Benedetto ${ }^{4}$ \\ CIRA, Italian Aerospace Research Center, Via Maiorise, 81043 Capua (CE), Italy. \\ Victor Fernandez Villace ${ }^{5}$, Johan Steelant ${ }^{6}$ \\ ESA-ESTEC, European Space Agency, Keplerlaan 1, 2200 AZ Noordwijk, The Netherlands. \\ Anatoly Gubanov ${ }^{7}$, Nina Voevodenko ${ }^{8}$ \\ Central Aerohydrodynamic Institute named after Prof. N.E. Zhukovsky (TsAGI), 140180 Zhukovsky, Russian Federation \\ Bodo Reimann ${ }^{9}$, \\ German Aerospace Center (DLR), Lilienthalplatz 7, 38108 Braunschweig, Germany. \\ and \\ Craig Walton ${ }^{10}$ \\ Gas Dynamics Ltd., GU148LX Farnborough, United Kingdom.
}

\begin{abstract}
As a fundamental step towards the development of a civil high-speed transport concept, the European Community (EC) co-funded HEXAFLY-INT international project (with partners from Europe, Russian Federation, Brazil and Australia), has the aim to design, manufacture and test in flight an innovative gliding hypersonic vehicle, based on the configuration developed in previous EC co-funded projects LAPCAT I, II and HEXAFLY.

The flight experiment is focused on a self-controlled glider configuration characterized by high aerodynamic efficiency and equipped with several breakthrough technologies on-board, in order to provide valuable aerodynamic and aero-structural flight data to validate methods and technologies used to design the hypersonic vehicle.

In this framework, this paper provides a detailed overview on research efforts carried out in assessing the aerodynamic performance of the expendable Experimental Flight Test Vehicle under development in the programme. Aerodynamic results are obtained by means of a massive number of CFD simulations of increasing level of accuracy and through an experimental test campaign carried out at TsAGI in their T-116 wind tunnel facility.
\end{abstract}

${ }^{1}$ Ph. D., Senior Research Engineer, Space Division, Technology Integration. m.marini@cira.it

${ }^{2} \mathrm{Ph}$. D., Research Engineer, Aerothermodynamic Section, Analysis and Extrapolation to Flight Lab., Head. g.pezzella@cira.it ${ }^{3}$ Senior Research Engineer, Aerothermodynamic Section, Head. a.schettino@cira.it

${ }^{4}$ Ph. D., Research Engineer, Aeronautics Division, System Engineering. s.dibenedetto@cira.it

${ }^{5} \mathrm{Ph}$. D., Research Engineer, ESA-ESTEC, Aerothermodynamics and Propulsion Analysis Section TEC-MPA. Victor.Villace@esa.int

${ }^{6} \mathrm{Ph}$. D., Senior Research Engineer, ESA-ESTEC, Aerothermodynamics and Propulsion Analysis Section TEC-MPA. Johan.Steelant@esa.int, AIAA Member

${ }^{7}$ Ph. D., Head of Division, TsAGI, Aerodynamics Department. Anatoly.Gubanov@tsagi.ru

${ }^{8}$ Ph. D., Head of Sector, TsAGI, Aerodynamics Department. Nina.Voevodenko@tsagi.ru

${ }^{9} \mathrm{Ph}$. D., Researcher, Institute of Aerodynamics and Flow Technology, Spacecraft. Bodo.Reimann@dlr.de

${ }^{10}$ Research Engineer, Gas Dynamics Ltd., cwalton@gasdynamics.co.uk 


\section{Nomenclature}

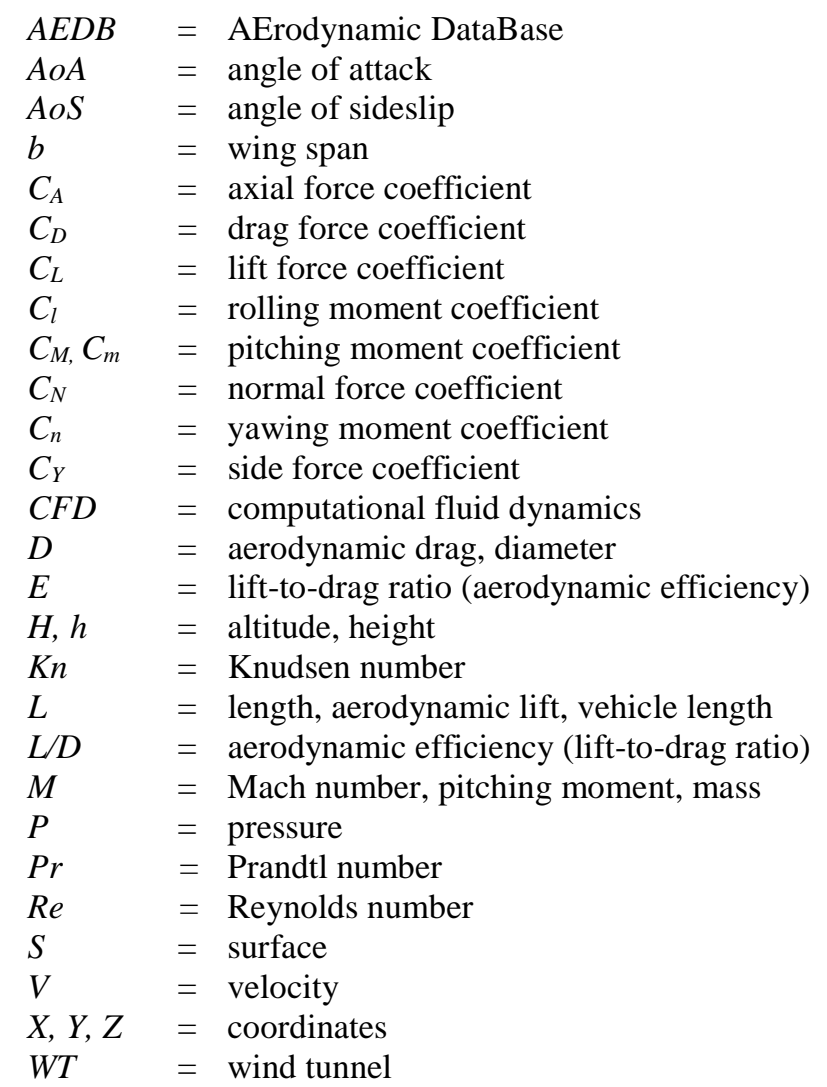

\section{Greek Symbols}

$\begin{array}{ll}\alpha & =\text { angle of attack } \\ \beta & =\text { angle of sideslip } \\ \Delta & =\text { variation } \\ \delta & =\text { aileron deflection } \\ \lambda & =\text { molecular mean free path } \\ \rho & =\text { density }\end{array}$

\section{Introduction}

CIRA, the Italian Aerospace Research Centre, with the European Space Agency (ESA) and several European partners, is

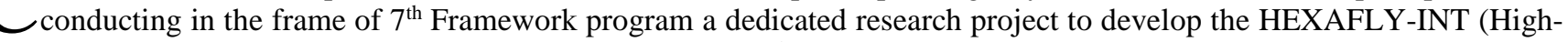
Speed Experimental Fly Vehicles- INTernational) vehicle ${ }^{1}$.

This research programme, co-funded by ESA, aims at the free flight testing of an innovative high-speed streamlined glider with several breakthrough technologies on board. This approach will create the basis to gradually increase the TRL level relevant to the design of hypersonic vehicles.

In order to mature the HEXAFLY-INT project, a scientific mission profile was worked within a precursor, Level-0 project, called HEXAFLY. This included a proof-of-concept, based upon a preliminary design of a high-speed scramjet propelled flight test vehicle, the selection and integration of the ground-tested technologies developed within LAPCAT I \& II, ATLLAS I \& II and other national programs, and the identification of the most promising flight platform(s $)^{2-11}$. A waverider-like configuration, namely Experimental Flight Test Vehicle (EFTV), was selected to allow for a hypersonic cruise or acceleration flight within the atmosphere ${ }^{1,2}$. 
Over the last years, several innovative concepts of civil high-speed transportation vehicles were proposed ${ }^{8-11}$. These vehicles have a strong potential to increase the cruise range efficiency at high Mach numbers, thanks to efficient propulsion units combined with high-lifting vehicle concepts.

Performing a test flight at hypersonic speed will be the only and ultimate proof to demonstrate the technical feasibility of these new promising concepts versus their range efficiency.

In this framework, this paper provides, after a general overview of the mission and vehicle requirements, a detailed overview on research efforts carried out in assessing the aerodynamic performance of the expendable EFTV, under development in the programme.

Aerodynamic results obtained by means of a massive number of CFD simulations with increasing level of accuracy, and through an experimental test campaign carried out at TsAGI in their T-116 wind tunnel (WT) facility, are provided and discussed in detail in the paper.

\section{Vehicle Description and Mission Profile}

The EFTV glider, shown in Figure 1, is a hypersonic waverider-like glider of $3.29 \mathrm{~m}$ long and with a wing span of about $1.24 \mathrm{~m}$. The EFTV has a two-dimensional nosetip with a $2 \mathrm{~mm}$ rounding and $2 \mathrm{~mm}$ lateral fillet, while the wing is characterized by a 80 deg sweep angle, a 14 deg negative dihedral angle and a $1 \mathrm{~mm}$ rounded leading edge.

The vehicle is equipped by a couple of active ailerons ( $0.4 \mathrm{~m}$ long and $0.32 \mathrm{~m}$ wide), which can be deflected in a symmetric and asymmetric way, and a couple of fixed vertical fins for passive lateral-directional control characterized by a 68.5 deg sweep angle and a 54 deg angle formed between the two fins in the transversal plane.

The present aeroshape of the EFTV is the result of an evolution, fully described in Ref. 1 and Ref. 13, started at the project kick-off (April 2014). Following the indications suggested by the continuous aero-heating assessment, mainly the nosecap and forebody configuration, the wing leading edge and the wing-fuselage intersection, and the aileron shape and edges were adapted $^{13}$.

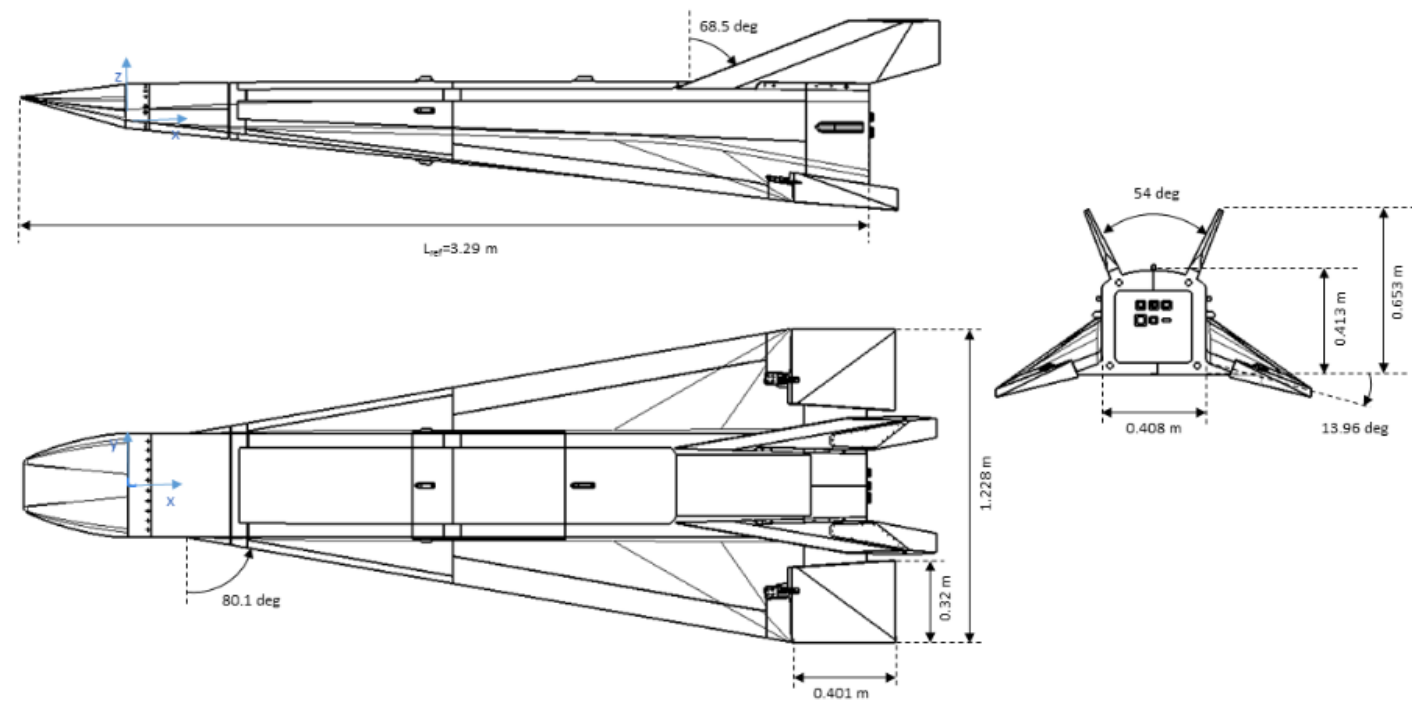

Figure 1. EFTV three-view drawing.

The glider vehicle will be launched by a sounding rocket, the Brazilian VS43 launcher equipped by a 8-ton solid rocket motor, in a suborbital trajectory having an apogee at around $90 \mathrm{~km}$ and Mach 8.

The vertical launch is planned from the Centro de Lançamento de Alcântara (CLA) in Brazil. In the first part of the trajectory the EFTV is docked to an Experimental Support Module (ESM), see Figure 2, which will control vehicle's attitude at high altitude by means of a cold gas system (CGS) in combination with the advantages coming from the aerodynamic flare configuration ${ }^{\mathbf{1}}$. 


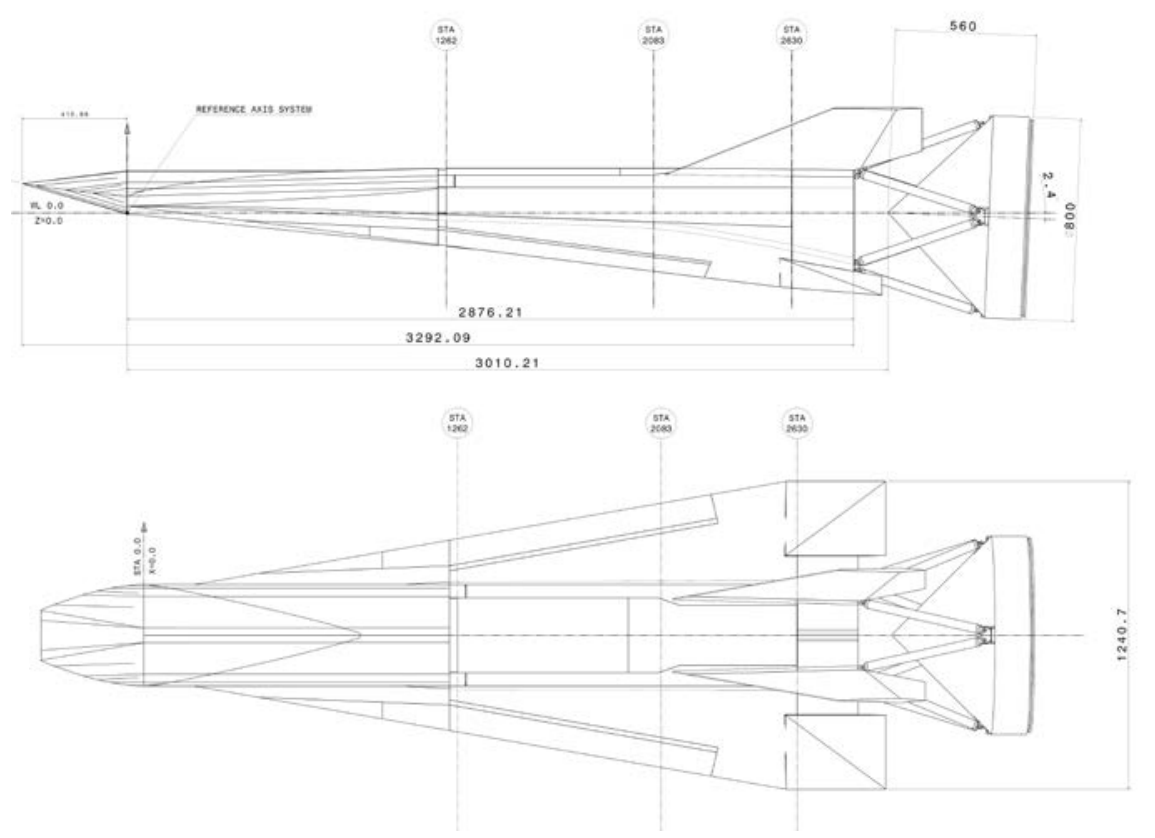

Figure 2. EFTV+ESM configuration.

A qualitative mission scenario for the HEXAFLY-INT project with the most important flight phases is shown in the following Figure 3.

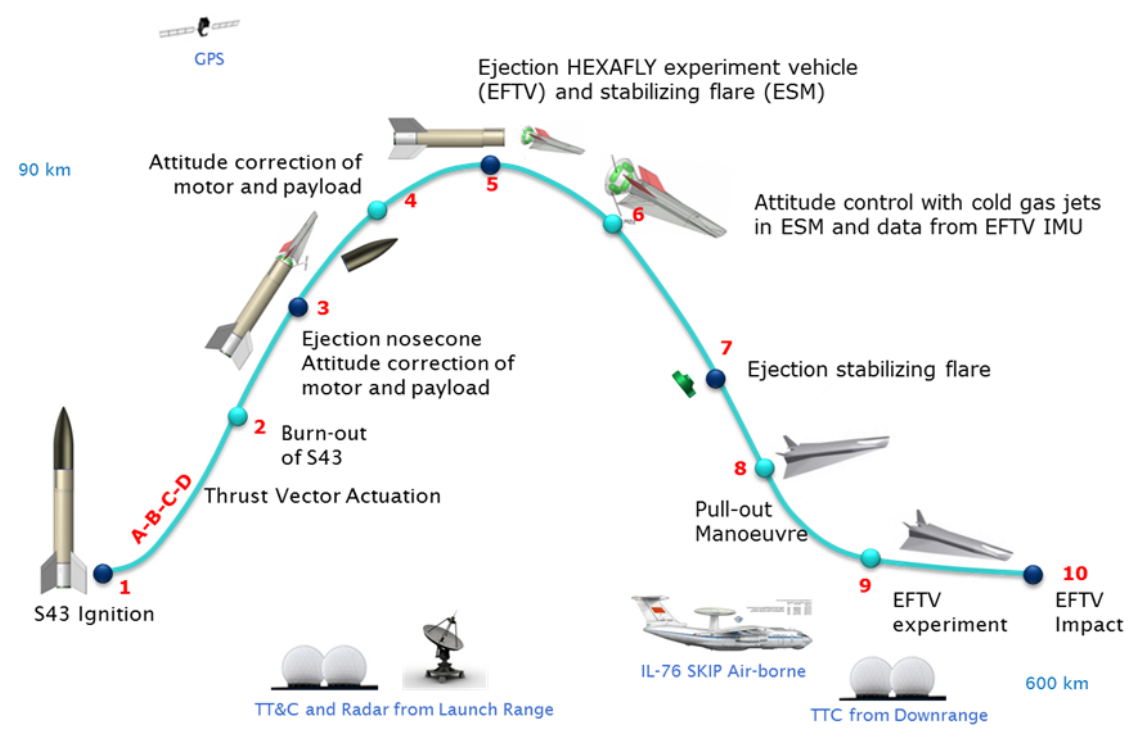

Figure 3. HEXAFLY-INT qualitative mission scenario.

As one can see, after a boost provided by an expendable launch vehicle equipped by a solid rocket motor (S43), bringing the scientific payload (EFTV+ESM) to about $90 \mathrm{~km}$ apogee, the EFTV will perform the early descent flight docked to the ESM and will undock at about $50 \mathrm{~km}$ altitude, thus performing a hypersonic cruise.

Details of the reference mission scenario are summarized from Figure 4 to Figure 6, where the preliminary reference trajectory is shown. Indeed, after the separation a pull-out manoeuver brings EFTV to a hypersonic levelled flight at approximately Mach 7 and at an altitude of about $30 \mathrm{~km}{ }^{1}$

\section{4}

American Institute of Aeronautics and Astronautics 


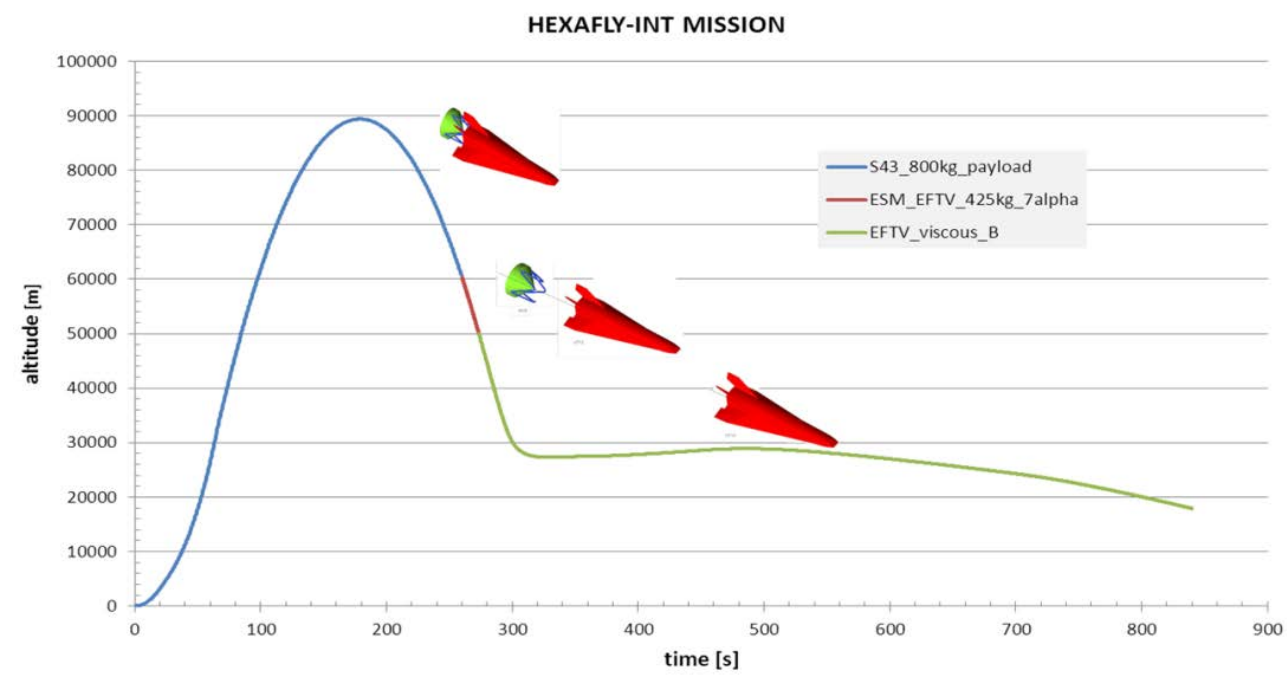

Figure 4. Overall altitude time history.

The Mach number time history is shown in Figure 5, while the overall time histories of AoA and aileron trim deflections are provided in Figure 6.

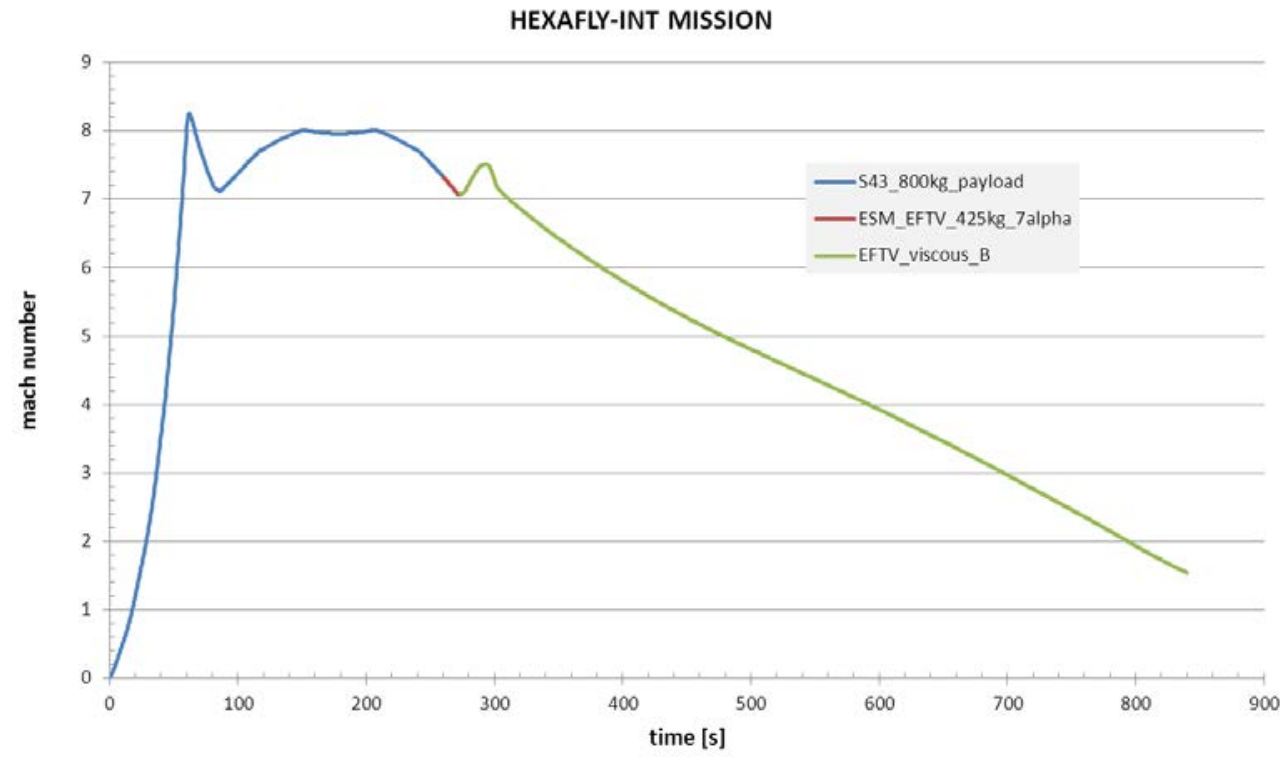

Figure 5. Overall Mach number time history.

Note that these preliminary trajectories have been generated by DLR-Moraba related the launch vehicle, assuming a total payload weight of $800 \mathrm{~kg}$ (EFTV, ESM, launch vehicle service module, fairing) for the S43 booster. Gas Dynamics Ltd. (GDL) provided the follow-up trajectory for the joint EFTV+ESM combination from $60 \mathrm{~km}$ to $50 \mathrm{~km}$ altitude and for the EFTV after the separation from ESM from $50 \mathrm{~km}$ to about $20 \mathrm{~km}$ altitude.

5

American Institute of Aeronautics and Astronautics 


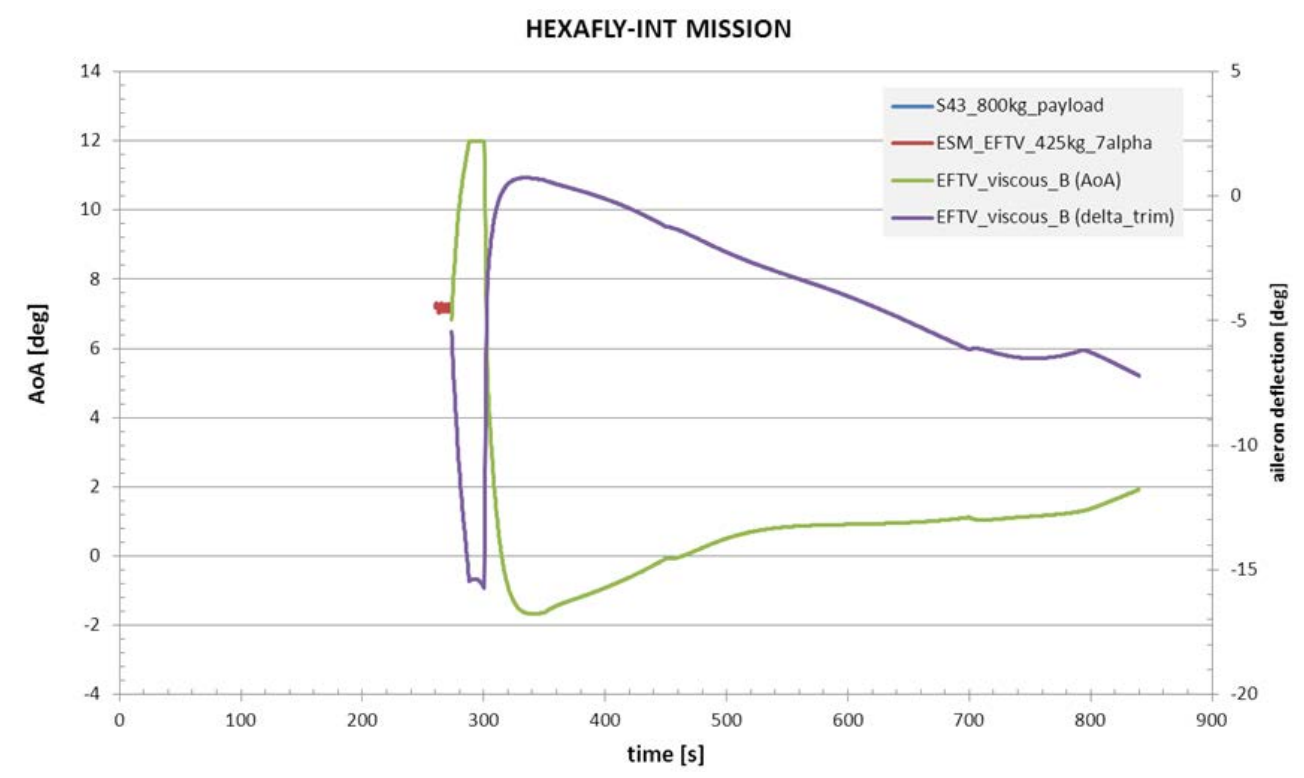

Figure 6. Overall time histories of AoA and aileron trim deflection.

\section{A. Flight regime assessment}

During a re-entry, a vehicle can generally experience three main flow regimes according to Bird's classification ${ }^{12}$. During the upper part of descent trajectory, one is faced with the free molecular and the transitional flow regime, whereas a continuum flow regime is experienced within the lower atmospheric layers (see Figure 7).

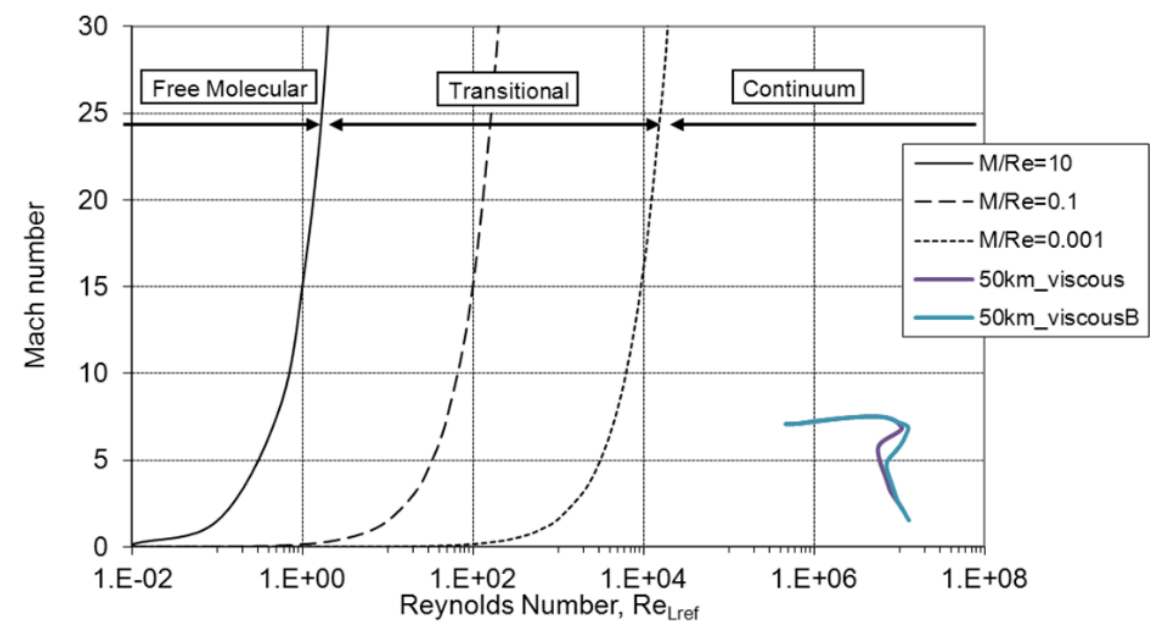

Figure 7. Flight regime assessment.

This figure provides the preliminary reference EFTV flight envelope (50 km-viscous B) in the Mach-Reynolds numbers map. The similarity parameter governing these different flow regimes is the Knudsen number, defined as (rarefaction parameter):

$$
K n_{\infty L_{r e f}}=\frac{\lambda}{L_{r e f}}=1.25 \sqrt{\gamma} \frac{M_{\infty}}{R e_{\infty L_{r e f}}}
$$

6

American Institute of Aeronautics and Astronautics 
where $\mathrm{L}_{\mathrm{ref}}$ is the characteristic length of the body and $\lambda$ is the molecular mean free path. As shown in Figure 7, the region for $10^{-3}<\mathrm{Kn}_{\infty}<10$ is the rarefied-flow transition region. Figure 7 points out clearly that only continuum flow conditions are expected for the EFTV throughout its mission. As a consequence, the glider aerodynamic appraisal will be addressed for continuum flow conditions only. With this in mind, the Reynolds and Mach numbers scenarios are assessed to allow for defining vehicle aerodynamics. Indeed, the EFTV flight envelope in the altitude-velocity map is shown Figure 8, where isoMach and iso-Reynolds curves are also provided, as well.

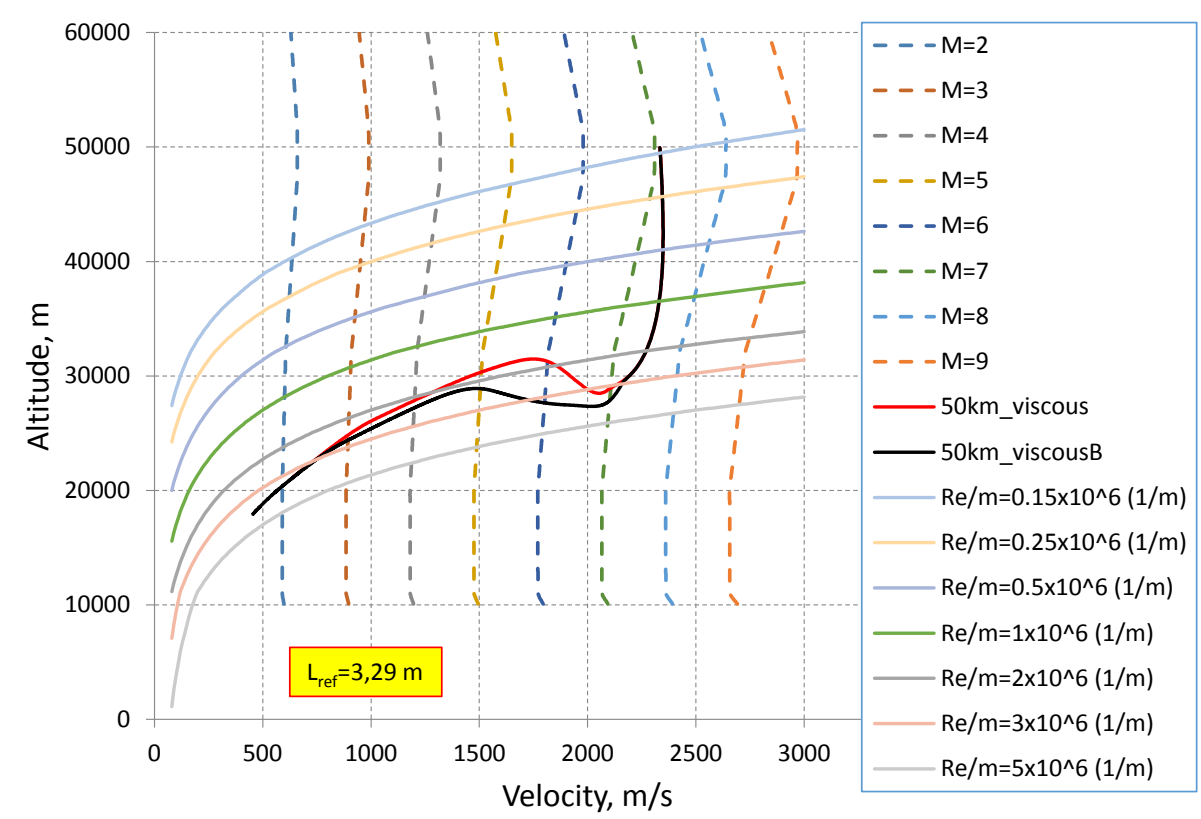

Figure 8. Constant Mach and Reynolds lines in the altitude-velocity map.

\section{Aerodynamic Database Development of EFTV Glider}

The aerodynamic analysis of EFTV is reported hereinafter in term of lift $\left(\mathrm{C}_{\mathrm{L}}\right)$, drag $\left(\mathrm{C}_{\mathrm{D}}\right)$, side force $\left(\mathrm{C}_{\mathrm{Y}}\right)$, rolling moment $\left(\mathrm{C}_{l}\right)$, pitching moment $\left(\mathrm{C}_{\mathrm{m}}\right)$, and yawing moment $\left(\mathrm{C}_{\mathrm{n}}\right)$ coefficients, which are calculated according to the following equations.

$$
\begin{gathered}
C_{i}=\frac{F_{i}}{\frac{1}{2} \rho_{\infty} V_{\infty}^{2} S_{r e f}} \quad i=L, D, Y \\
C_{l}=\frac{M_{x}}{\frac{1}{2} \rho_{\infty} V_{\infty}^{2} b_{r e f} S_{r e f}} \\
C_{m}=\frac{M_{y}}{\frac{1}{2} \rho_{\infty} V_{\infty}^{2} L_{r e f} S_{r e f}} \\
C_{n}=\frac{M_{z}}{\frac{1}{2} \rho_{\infty} V_{\infty}^{2} b_{r e f} S_{r e f}}
\end{gathered}
$$

The moment reference centre (MRC) for the calculation of the aerodynamic moment coefficients is shown in Figure 9 with respect to the Layout Reference Frame (LRF). 


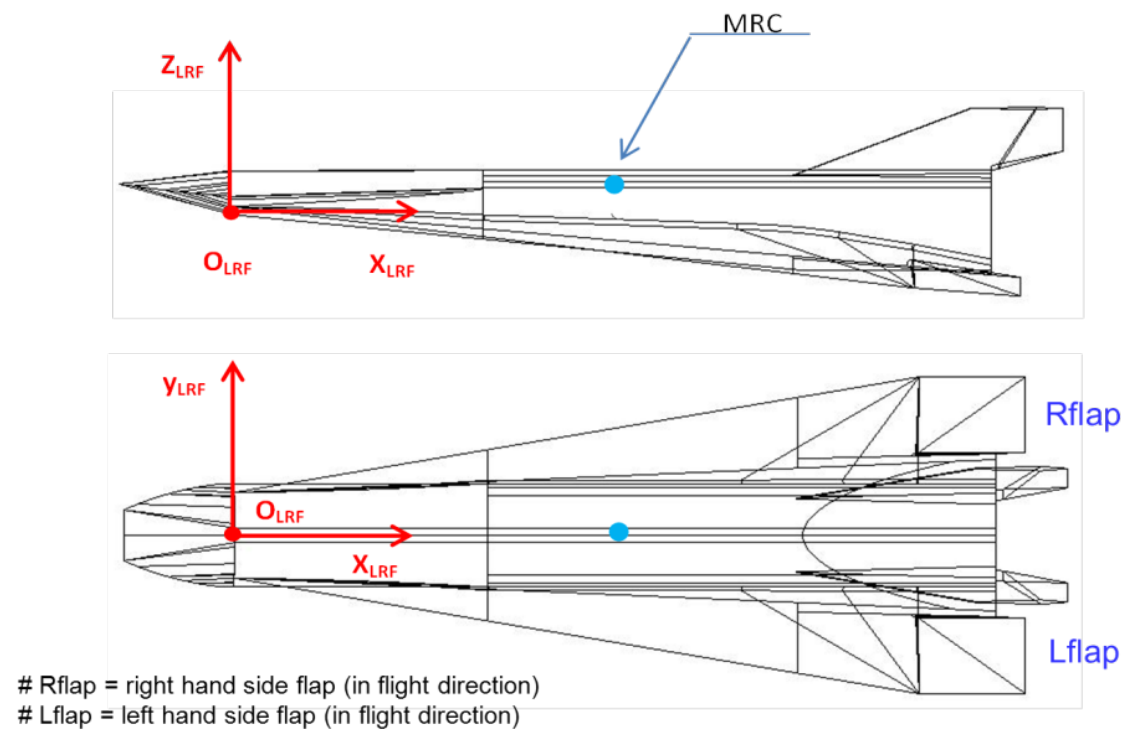

Figure 9. The Layout Reference Frame.

Thus, the MRC coordinates in LRF for the EFTV are $(1.455,0,0.120)$ [m].

In particular, $C_{L}$ and $C_{D}$ are provided in the vehicle's wind reference frame (WRF), while $C_{Y}, C_{l}, C_{m}$, and $C_{n}$ are evaluated in the vehicle's body reference frame (BRF) shown in Figure 10.

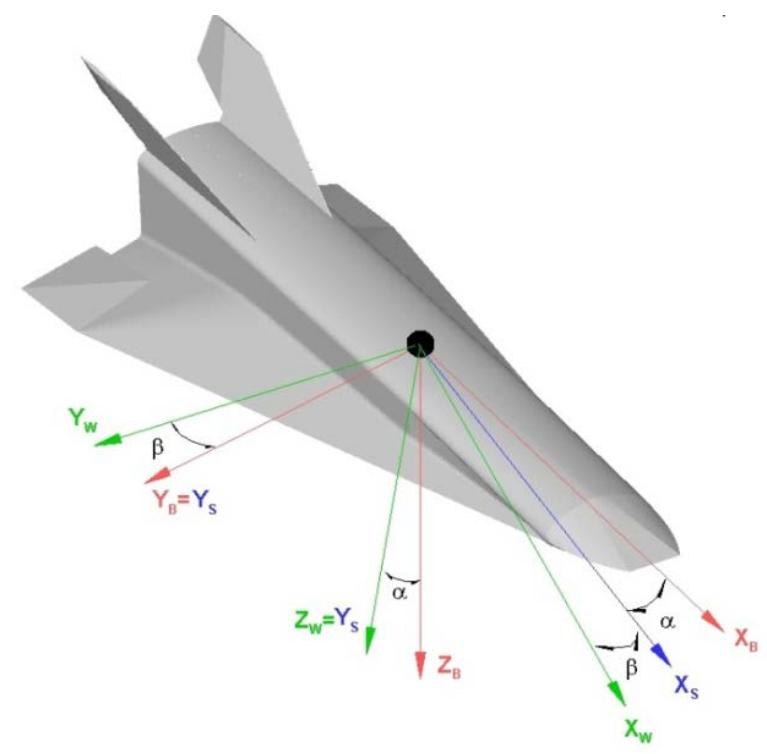

Figure 10. The wind reference frame $\left(X_{w}, Y_{w}, Z_{w}\right)$ and the body reference frame $\left(X_{B}, Y_{B}, Z_{B}\right)$.

\section{A. General inputs for Aerodynamic Database generation}

The following reference parameters have been considered for the generation of the Aerodynamic Database (AEDB) of EFTV (see Figure 11): $\mathrm{L}_{\mathrm{ref}}=3.29 \mathrm{~m}$ (i.e. body length - longitudinal reference length); $\mathrm{b}_{\mathrm{ref}}=1.24 \mathrm{~m}$ (i.e. wing span - lateraldirectional reference length); $\mathrm{S}_{\text {ref }}=2.52 \mathrm{~m}^{2}$ (i.e. vehicle planform area - reference area). 


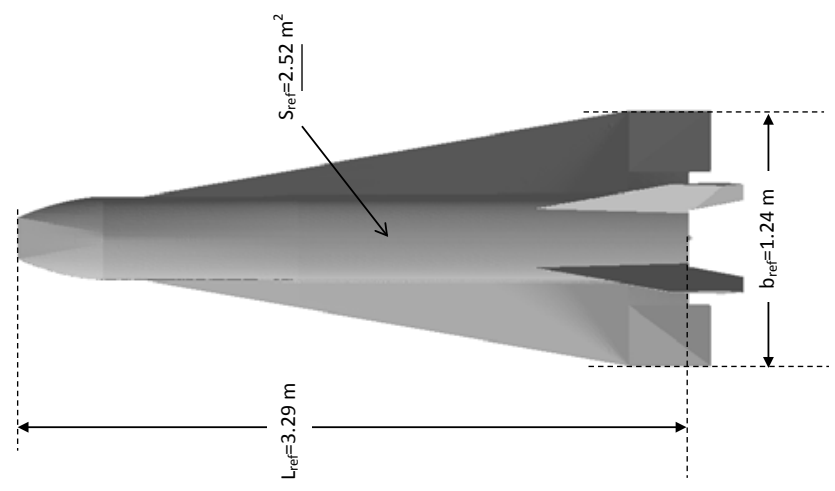

Figure 11. Reference quantities for EFTV aerodynamics.

\section{B. Aerodynamic force and moments definitions and signs rules}

In Figure 12 the adopted reference frame (BRF) with aerodynamic coefficients conventions are shown. The reference system for the aerodynamic data is a body-fixed axis system, compliant with the ISO 1151 standard.

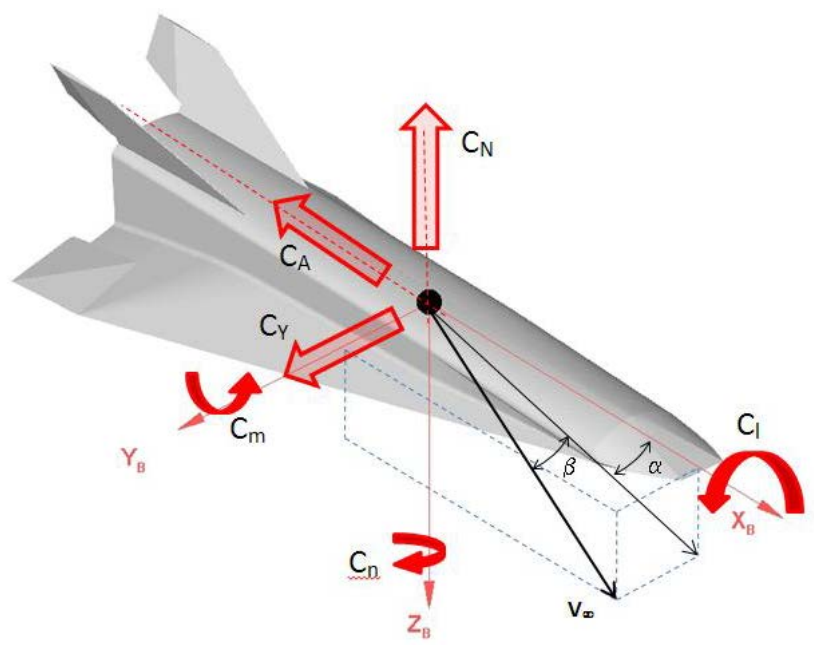

Figure 12. Reference frame and aerodynamic coefficients convention.

Directions of force and moment coefficients on the figure are positive as shown in Figure 12. The following aerodynamic sign convention for forces, moments, velocities, and accelerations is adopted (see Figure 10 and Figure 12):

- Angle of attack $(\alpha)$ is positive when free stream arrives from down of the pilot;

- Sideslip angle $(\beta)$ is positive when free stream arrives from right of the pilot;

- Aileron deflection angle $\left(\delta_{\mathrm{a}}\right)$ is positive when trailing edge is down;

- Elevon deflection angle $\left(\delta_{\mathrm{e}}\right)$ is positive when trailing edge is down;

- Axial force coefficient $\left(\mathrm{C}_{\mathrm{A}}\right)$ is positive when force is pushing in front of vehicle toward the base;

- Normal force coefficient $\left(\mathrm{C}_{N}\right)$ is positive when force is pushing on belly side of vehicle toward up;

- Side force coefficient $\left(\mathrm{C}_{\mathrm{Y}}\right)$ is positive when force is pushing on left side of vehicle toward the right;

- Rolling moment coefficient $\left(\mathrm{C}_{l}\right)$ is positive when right wing is down;

- Pitching moment coefficient $\left(\mathrm{C}_{\mathrm{m}}\right)$ is positive when the aircraft puts the nose up;

- Yawing moment coefficient $\left(\mathrm{C}_{n}\right)$ is positive when right wing is backward.

Note that this is the convention usually adopted in flight mechanics. For the sake of clarity, additional illustrations about aerodynamic signs convention are also provided in Figure 13. 


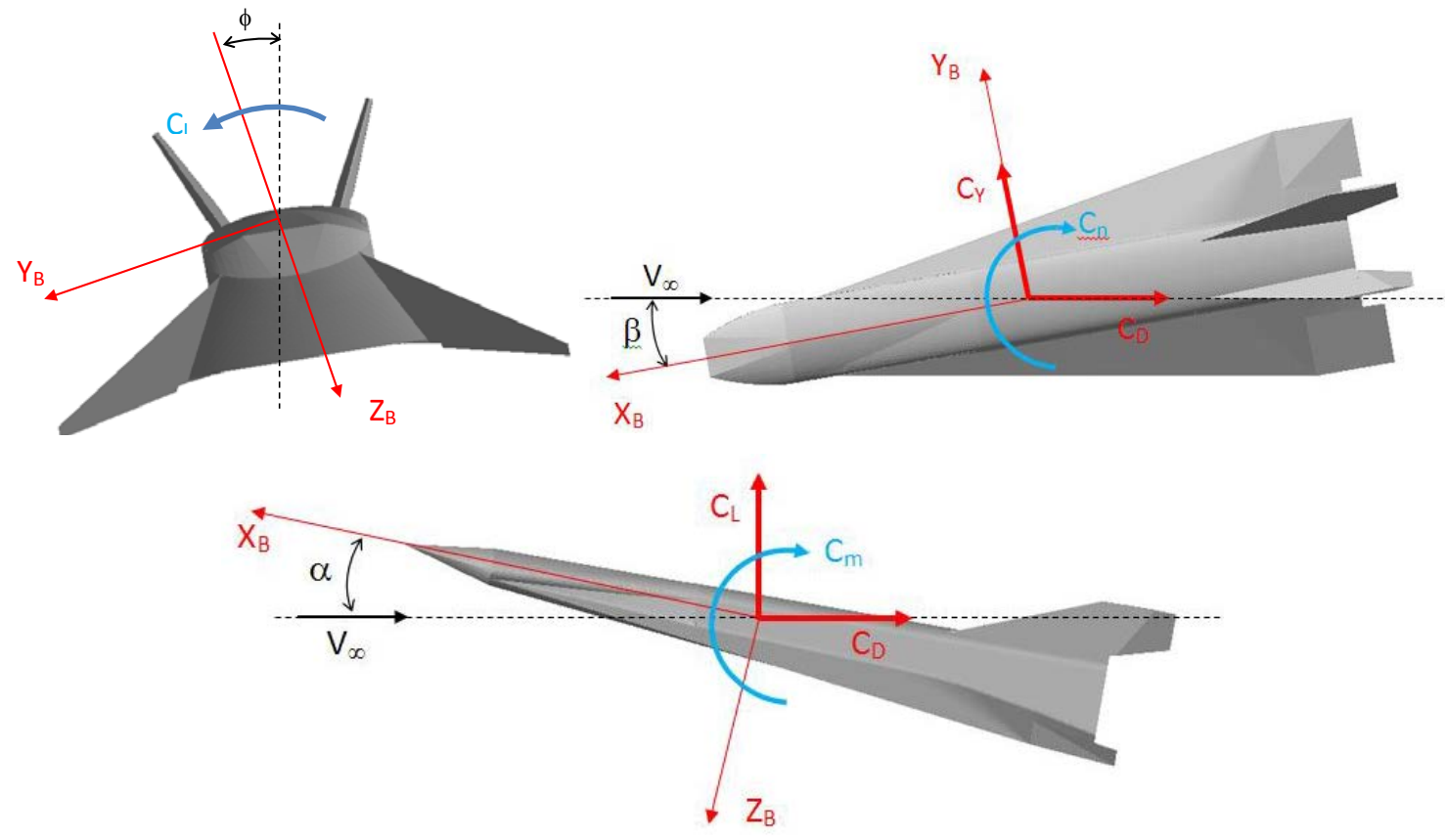

Figure 13. Aerodynamic coefficients convention and sign rule.

Therefore, the aerodynamic static stability conditions, expressed in terms of derivatives, are the following: $\mathrm{C}_{\mathrm{m} \alpha}<0$, for longitudinal stability; and $\mathrm{C}_{\mathrm{Y} \beta}<0, \mathrm{C}_{\mathrm{n} \beta}>0, \mathrm{C}_{\mathrm{l} \beta}<0$, for lateral-directional stability.

\section{CFD Analysis}

Glider aerodynamic database (AEDB) was setup by CIRA using a massive number of CFD computations performed by several programme's partners, as DLR, ESA, CIRA and TsAGI.

The detailed content of CFD test matrix performed by DLR is reported in Table 1, for a total number of 1305 CFD Eulerian simulations ${ }^{13}$.

\begin{tabular}{|c|c|c|c|c|}
\hline Mach & $\begin{array}{c}\text { AoA } \\
\text { [deg] }\end{array}$ & $\begin{array}{c}\text { AoS } \\
{[\operatorname{deg}]}\end{array}$ & $\begin{array}{c}\delta \\
{[\operatorname{deg}]}\end{array}$ & $\begin{array}{l}\text { no. of } \\
\text { runs }\end{array}$ \\
\hline $2 \div 9, \Delta \mathrm{M}=1$ & $-6 \div 12, \Delta \alpha=2$ & 0 & $-20 \div 5, \Delta \delta=5$ & 480 \\
\hline $2 \div 9, \Delta \mathrm{M}=1$ & $-6 \div 12, \Delta \alpha=2$ & 2 & $-20 \div 5, \Delta \delta=5$ & 480 \\
\hline $2 \div 8, \Delta \mathrm{M}=2$ & $0,6,12$ & 4,8 & 0 & 24 \\
\hline $3,5,7$ & $0,6,12$ & 0,4 & $\begin{array}{c}\delta \mathrm{l}=-5, \delta_{\mathrm{r}}=-20,-15,-10,5 \text { and } \\
\delta_{\mathrm{r}}=5, \delta_{\mathrm{l}}=-20,-15,-10\end{array}$ & 126 \\
\hline 7 & $0,6,12$ & -4 & $\delta_{\mathrm{r}}=5, \delta \mathrm{l}=-20$ & 3 \\
\hline $3,5,7$ & $0,6,12$ & 0 & -25 & 9 \\
\hline $3,5,7$ & $0,6,12$ & 2 & -25 & 9 \\
\hline $3,5,7$ & 0,6 & 4 & $-25,-15,-10,-5,5$ & 30 \\
\hline $3,5,7$ & 0,6 & 2 & $\delta_{\mathrm{l}}=-25, \delta_{\mathrm{r}}=-20,-15,-10,-5,5$ & 60 \\
\hline $3,5,7$ & 0,6 & 0,4 & $\delta_{\mathrm{l}}=-20, \delta_{\mathrm{r}}=-10,5$ and $\delta_{\mathrm{l}}=-5, \delta_{\mathrm{r}}=-20$ & 36 \\
\hline $3,5,7$ & 0,6 & -4 & $\begin{array}{c}\delta_{\mathrm{l}}=-25, \delta_{\mathrm{r}}=-10 \text { and } \delta_{\mathrm{l}}=-20, \delta_{\mathrm{r}}=-10,5 \\
\text { and } \delta_{\mathrm{l}}=-5, \delta_{\mathrm{r}}=-20,-10,5 \text { and } \delta_{\mathrm{l}}=0, \\
\delta_{\mathrm{r}}=-20,-15\end{array}$ & 48 \\
\hline
\end{tabular}

Table 1. Inviscid AEDB by DLR.

In order to improve this Eulerian aerodatabase (see Table 1), an additional 236 fully turbulent CFD simulations were performed ESA, CIRA and TsAGI summarized in both Table 2 and Table 3.

10

American Institute of Aeronautics and Astronautics 
A first set of computations (Block\#9) was performed by CIRA along a preliminary EFTV reference trajectory, whose test matrix is reported in Table 2, with three main objectives:

$\checkmark \quad$ to verify the trim conditions along the preliminary reference trajectory;

$\checkmark \quad$ to provide mechanical and thermal loads as inputs for thermo-structural analyses;

$\checkmark \quad$ to provide surface distribution of pressure, heat flux and temperature for the in-flight measurement system design and layout optimization (DRL-Cologne).

\begin{tabular}{|c|c|c|c|c|c|c|c|c|c|c|c|}
\hline & Run ID & $\begin{array}{c}\mathrm{H} \\
(\mathrm{m})\end{array}$ & $\begin{array}{c}V \\
(\mathrm{~m} / \mathrm{s})\end{array}$ & $\underset{\left(\mathrm{kg} / \mathrm{m}^{3}\right)}{\rho}$ & $\begin{array}{c}T \\
(K)\end{array}$ & $\mathbf{M}$ & $\begin{array}{l}\text { AoA } \\
\text { (deg) }\end{array}$ & $\begin{array}{c}\mathbf{P} \\
(\mathrm{Pa})\end{array}$ & $\begin{array}{c}\delta \\
(\mathrm{deg})\end{array}$ & $\mathrm{Re}_{\mathrm{L}}$ & $\begin{array}{c}\mathrm{H}_{0} \\
(\mathrm{MJ} / \mathrm{kg})\end{array}$ \\
\hline \multirow[t]{2}{*}{$\begin{array}{l}\text { EFTV/ESM } \\
\text { separation } \\
\end{array}$} & EFTV-065 & 49942.00 & 2333.80 & 0.00104 & 270.65 & 7.076 & 6.83 & 80.359 & -5.46 & $4.665 E+05$ & 2.99 \\
\hline & EFTV-066 & 37716.85 & 2337.68 & 0.00560 & 244.03 & 7.465 & 12.00 & 392.181 & -15.44 & $2.746 \mathrm{E}+06$ & 2.98 \\
\hline $\begin{array}{c}\text { maximum } \\
\text { Mach }\end{array}$ & EFTV-067 & 35947.24 & 2325.39 & 0.00732 & 239.14 & 7.501 & 12.00 & 502.252 & -15.39 & $3.630 E+06$ & 2.94 \\
\hline $\begin{array}{l}\text { maximum heat } \\
\text { flux @ nosetip }\end{array}$ & EFTV-068 & 33059.99 & 2288.09 & 0.01147 & 231.14 & 7.507 & 12.00 & 760.605 & -15.38 & $5.754 \mathrm{E}+06$ & 2.85 \\
\hline $\begin{array}{c}\text { maximum AoA, } \\
\text { g-load }\end{array}$ & EFTV-069 & 29936.43 & 2187.90 & 0.01859 & 226.45 & 7.253 & 12.00 & 1208.457 & -15.72 & $9.075 E+06$ & 2.62 \\
\hline \multirow[t]{2}{*}{ maximum L/D } & EFTV-070 & 28652.17 & 2136.93 & 0.02267 & 225.17 & 7.104 & 3.62 & 1465.014 & -2.02 & $1.086 \mathrm{E}+07$ & 2.51 \\
\hline & EFTV-071 & 28040.09 & 2112.00 & 0.02493 & 224.57 & 7.030 & 1.63 & 1606.457 & -0.68 & $1.182 \mathrm{E}+07$ & 2.46 \\
\hline \multirow[t]{4}{*}{$\begin{array}{c}\text { maximum dyn. } \\
\text { pressure, } R_{\mathrm{L}}\end{array}$} & EFTV-072 & 27461.55 & 2066.64 & 0.02727 & 223.99 & 6.888 & -0.66 & 1753.112 & 0.41 & $1.269 \mathrm{E}+07$ & 2.36 \\
\hline & EFTV-073 & 27444.96 & 1928.32 & 0.02734 & 223.98 & 6.427 & -1.63 & 1757.515 & 0.64 & $1.187 \mathrm{E}+07$ & 2.08 \\
\hline & EFTV-074 & 28854.96 & 1446.28 & 0.02197 & 225.37 & 4.806 & 0.51 & 1421.038 & -2.25 & $7.115 E+06$ & 1.27 \\
\hline & EFTV-075 & 25720.26 & 1034.27 & 0.03580 & 222.27 & 3.461 & 0.97 & 2283.671 & -5.04 & $8.388 E+06$ & 0.76 \\
\hline end of mission & EFTV-076 & 20384.69 & 591.17 & 0.08360 & 216.97 & 2.002 & 1.31 & 5206.060 & -6.17 & $1.142 \mathrm{E}+07$ & 0.39 \\
\hline
\end{tabular}

Table 2. Viscous CFD by CIRA (Block\#9).

After these preliminary computations, a more complete test matrix was simulated by CIRA, ESA and TsAGI in order to improve the glider aerodatabase and possibly reduce the uncertainties with respect to the first version ${ }^{14}$. The complete set of computations is summarized in Table 3.

\begin{tabular}{|l|c|c|c|c|}
\hline Block & Runs & CIRA & ESA & TsAGI \\
\hline 1: A.M. (M, AoA, aileron) \#1 & 120 & $60 @$ Ma 2,6 & 60 @ Ma 4, 7.5 & \\
\hline 2: A.M. (sideslip) & 24 & & 24 @ Ma 4, 7.5 & \\
\hline 3: A.M. (asym. ailerons) & 12 & & 12 @ Ma 4, 7.5 & \\
\hline 4: M.U. (Re effect) & 12 & & & 12 \\
\hline 5: M.U. (Grid effects, unstructured) & 9 & & & 9 \\
\hline 6: M.U. (Turbulence mod.) & 18 & & & 18 \\
\hline 7: M.U. (LtT transition) & 18 & & & 18 \\
\hline 8: M.U. (code-to-code) & 11 (of block\#1) & $\begin{array}{c}4 \text { @ Ma 4, 7.5 } \\
\text { 2 AoAs, 1 flap }\end{array}$ & $\begin{array}{c}4 \text { 2 AoAs, 1 flap } \\
\text { 2 }\end{array}$ & $\begin{array}{c}3^{+} \\
\text {(TBD) }\end{array}$ \\
\hline 9: Trajectory verification (Final) & 12 & 12 & & \\
\hline TOTAL & $\mathbf{2 3 6}$ & $\mathbf{7 6}$ & $\mathbf{1 0 0}$ & $\mathbf{6 0}$ \\
\hline
\end{tabular}

Table 3. Viscous CFD provided by ESA, CIRA and TsAGI.

As indicated by this test matrix, several fundamental aspects for AEDB development are addressed such as effects of Reynolds number, turbulence models, laminar-to-turbulence transition, different CFD numerical grids as well as code-to-code comparisons.

11

American Institute of Aeronautics and Astronautics 
CIRA simulations were performed with the commercial code ANSYS FLUENT ${ }^{\circledR}$, assuming a perfect gas behaviour with specific heat at constant pressure modelled with a polynomial function of temperature. For the turbulent cases the SpalartAllmaras model was used, while the wall has been assumed in radiative equilibrium condition, with surface emissivity coefficient $\varepsilon=0.4$ (except for $\mathrm{M}=2$ case where adiabatic wall boundary condition was considered) ${ }^{14}$.

Computational unstructured grids have a typical dimension of about 10-million cells for half configuration. Examples of surface grid and pressure contours are shown in Figure 14 and Figure 15, while in Figure 16 wall pressure and heat flux profiles on the symmetry plane for most of the simulated conditions of Table 2 are plotted ${ }^{14}$.
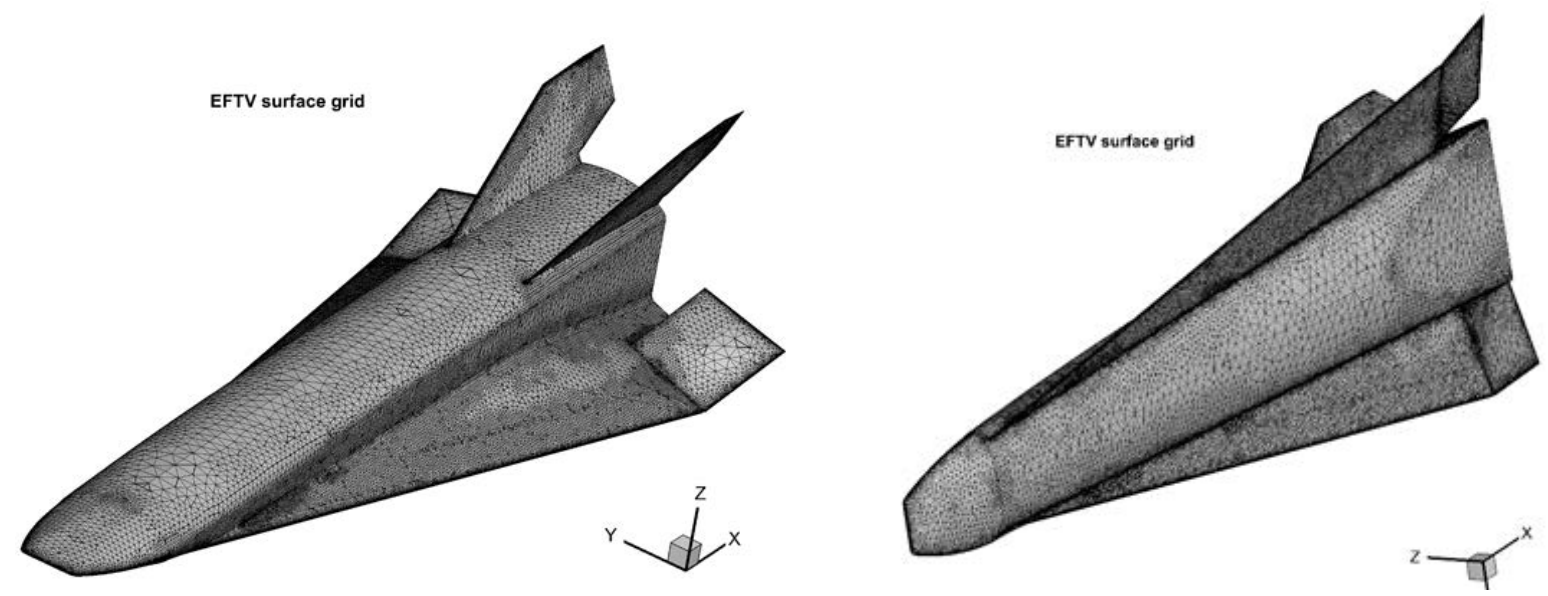

Figure 14. EFTV surface grid.
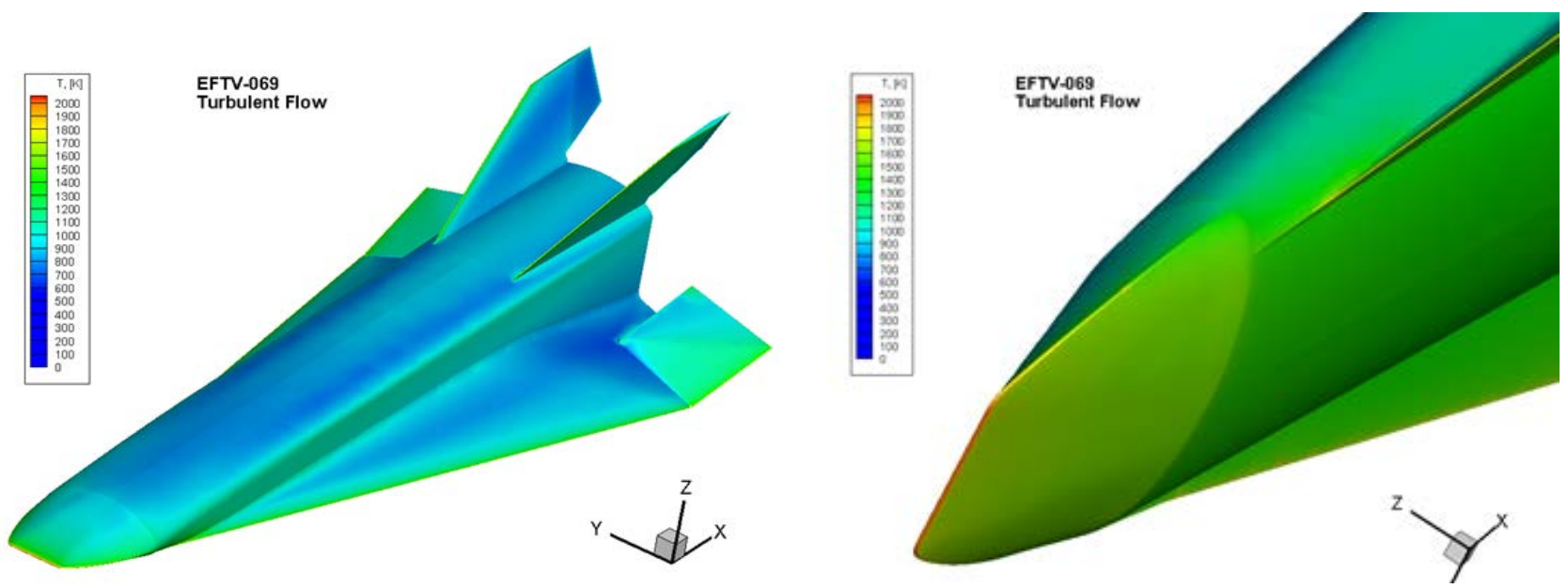

Figure 15. EFTV surface temperature contours (29.93 km, $\left.M=7.25, A o A=12 \mathrm{deg}, \delta_{\mathrm{e}}=-15.72 \mathrm{deg}\right)$ on full vehicle (left) and vehicle's forebody region (right). 

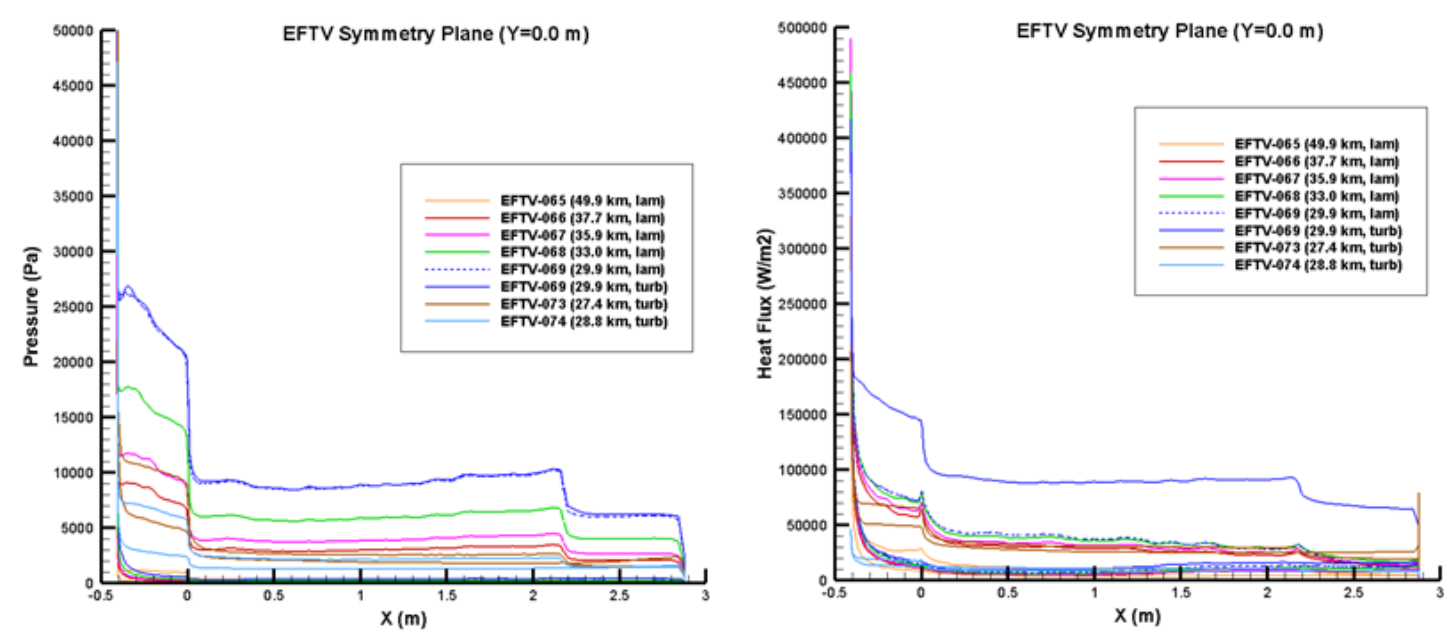

Figure 16. EFTV pressure (left) and heat flux (right) distributions at Y=0.0 m section.

The simulations by ESA were based on a hybrid grid of varying sizes between 4.4 and 5.6 million nodes (12.2 to 16.2 million elements) depending on the aileron deflection angle. A full domain, roughly twice as large, was considered for the cases of sideslip angle and asymmetrical flap deflection.

The surface grid was unstructured triangular but for the leading edges of nose, wings, ailerons and vertical fins. A structured-squared grid was considered for improved reconstruction of the peak heat fluxes over these surfaces. The grid refining in the boundary layer consisted on a prismatic extrusion of the surface mesh up to $37 \mathrm{~mm}$ or $55 \mathrm{~mm}$ from the wall, depending on the first cell height. The height of the first cell ranged from $10 \mu \mathrm{m}$ to $15 \mu \mathrm{m}$ (decreased further to $5 \mu \mathrm{m}$ on the leading edges). The prismatic extrusion comprised 40 cells with increasing height from the wall at a stretching ratio of 1.17.

For example, Figure 17 shows an overview of the surface and prismatic meshes (on the left), with detail of the mesh at the fuselage/aileron gap (on the right).
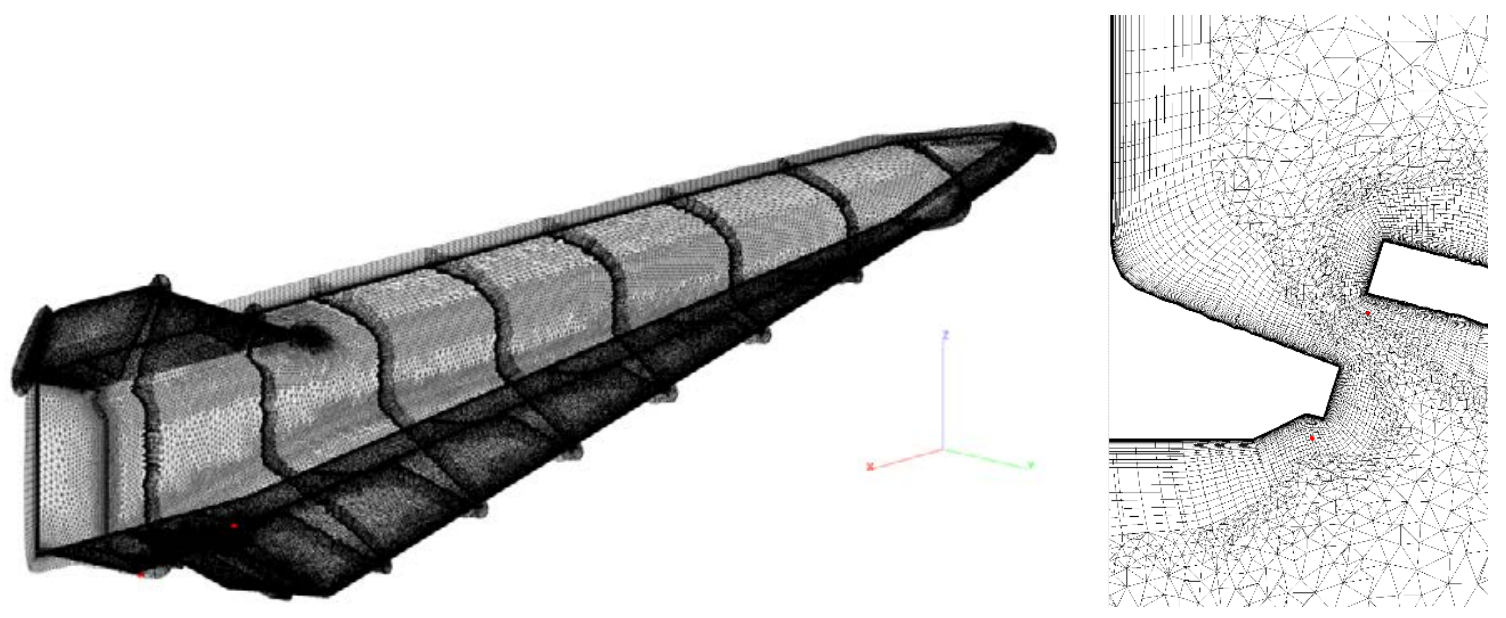

Figure 17. EFTV surface and prismatic meshes (left) and mesh enlargement at the fuselage/aileron gap (right).

The flow field was resolved with the code TAU of DLR ${ }^{15}$. The air thermal and transport properties were computed under the assumption of chemical equilibrium with five species, namely $\mathrm{N}_{2}, \mathrm{O}_{2}, \mathrm{NO}, \mathrm{N}$ and $\mathrm{O}$.

The originally proposed model by Spalart and Allmaras provided the turbulent closure of the RANS equations ${ }^{16}$. Since the laminar Pr number varies accordingly to the equilibrium model, a constant laminar to turbulent Prandtl number ratio of 0.8 was set to better approximate the turbulent part of the heat flux. The eddy to laminar viscosity ratio was set to 0.1 at the far-field and inflow boundaries. 
The fluxes in the Navier-Stokes equations and the eddy viscosity model were discretized accordingly to the upwind second-order AUSMDV scheme by Wada and Liou with a shock fix to prevent the carbuncle phenomenon ${ }^{17}$. A least-square reconstruction of the gradients is used, which proves more accurate than the Green-Gauss approach in case of hybrid grids ${ }^{18}$. Finally, the RANS equations were integrated towards the steady solution by means of a backward Euler time-relaxation scheme $^{19}$.

In addition, an analysis of laminar-to-turbulence natural transition along the reference trajectory has been performed by means of engineering criteria $^{7,8}$.

TsAGI CFD simulations of Table 3 have been performed by using ANSYS FLUENT ${ }^{\circledR}$ too. Computational grids have been built with 6-million, 13-million and 26-million cells for the symmetric EFTV half-body configuration, in particular to assess the effects of grid resolution ${ }^{14}$. Apart from the standard Spalart-Allmaras model, also the k- $\omega$ SST (TM1) and the k- $\varepsilon$ with the Menter-Lechner wall treatment (TM2) were used as turbulence models. With respect to transition modelling, the models implemented in ANSYS FLUENT ${ }^{\circledR}$ have been used: Langtry and Menter SST-Transition Model (Tran1) and Walters and Leylek k-kl- $\omega$ Transition Model (Tran2). Transition onset is completely automatic based on the Local Correlation-based Transition Modelling (LCTM) concept (Tran1) and the laminar kinetic energy (Tran2).

Standard ANSYS FLUENT ${ }^{\circledR}$ settings have been used for present simulations. Some exemplary results are shown in the following Figure 18 and Figure 19.
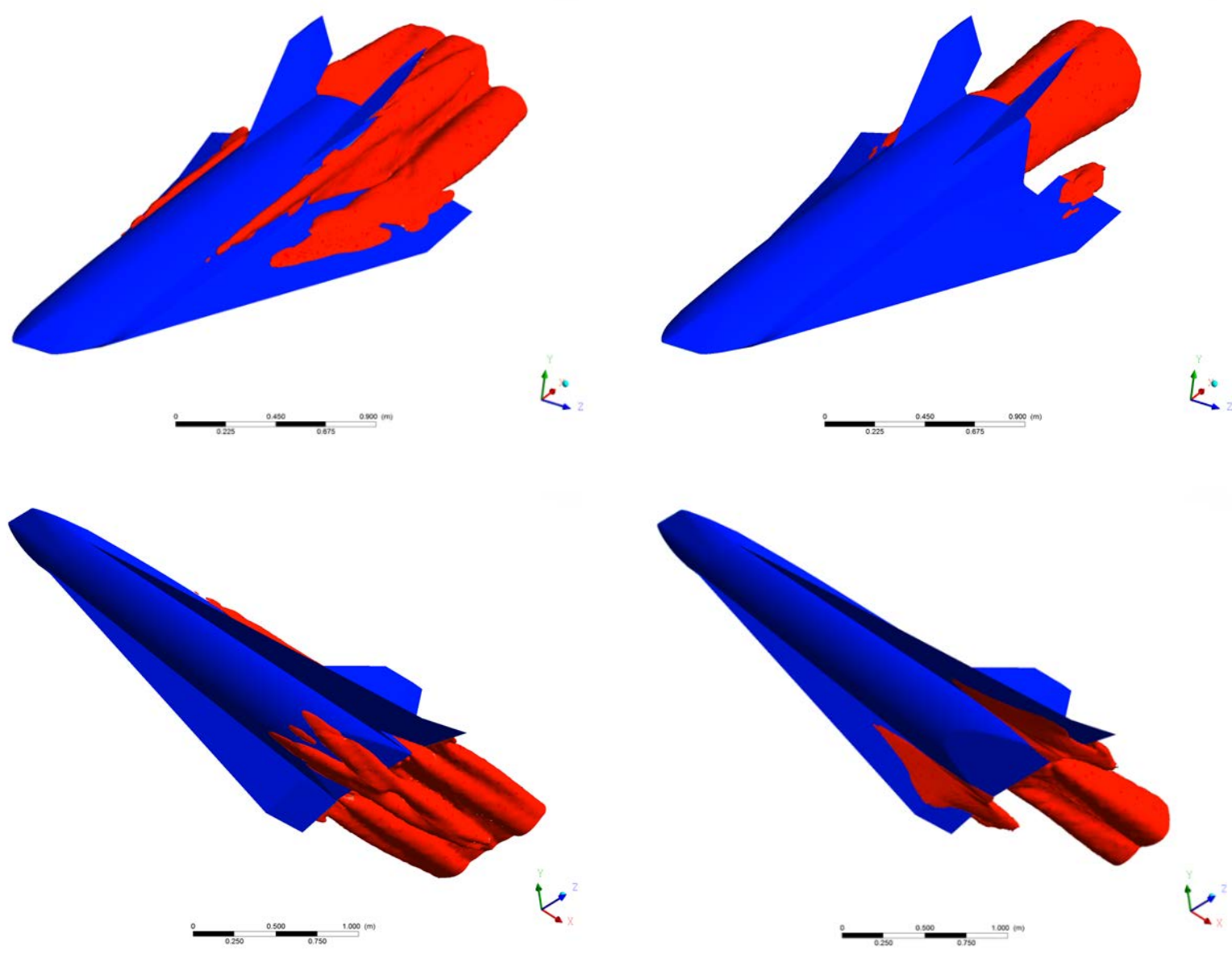

Figure 18. Predicted turbulent intensity (Tu) distribution in 3D volume (blue, $\mathrm{Tu}<0.5$; red, $\mathrm{Tu} \geq 0.5$ ), $\mathrm{M}=7.5, \mathrm{AoA}=0$ deg. Langtry and Menter SST-Transition Model (left) and Walters and Leylek k-kl-w Transition Model (right). 

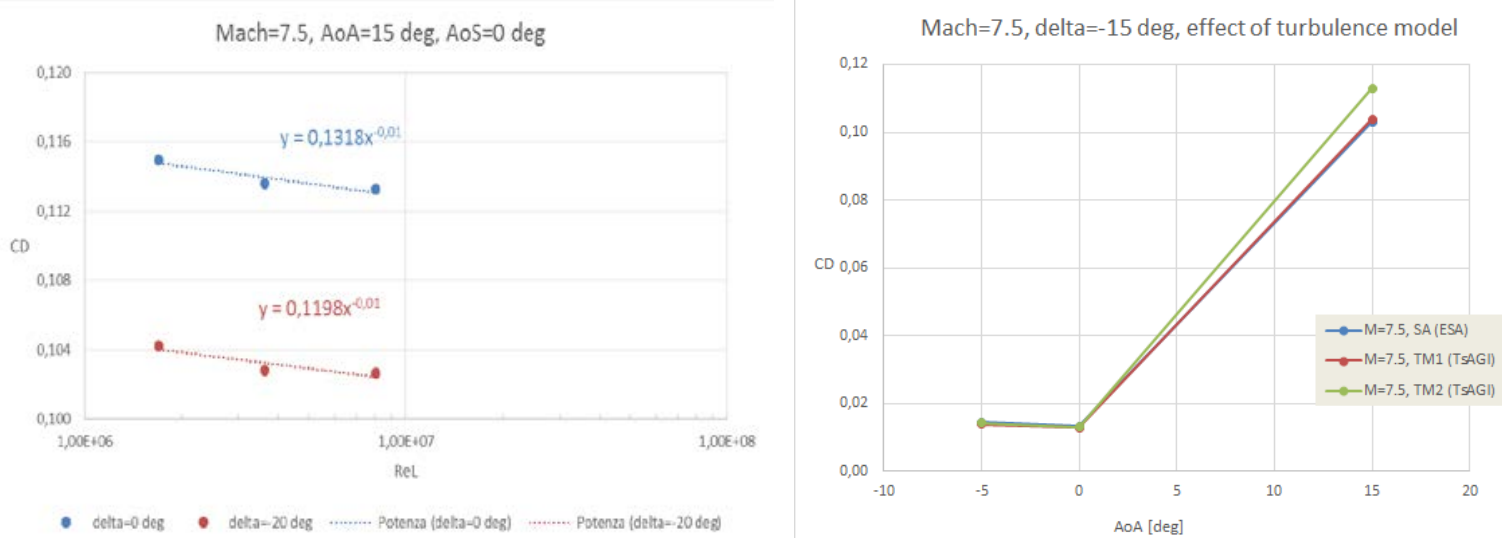

Figure 19. Reynolds number effect on $C_{D}$ at $M=7.5, A o A=15$ deg (left) and turbulence modelling effect on $C_{D}$ at $\mathrm{M}=7.5, \delta_{\mathrm{e}}=-15 \mathrm{deg}$ (right).

The main outcome of all these numerical results was that the glider is statically stable in both longitudinal and lateraldirectional flight, at all Mach numbers under investigation and for all angles of attack (AoA), angles of sideslip (AoS), and aileron deflections preliminarily considered. Some relevant plots (extracted by inviscid AEDB) of the moment (pitching, $\mathrm{C}_{\mathrm{m}}$, and yawing, $\mathrm{C}_{\mathrm{n}}$ ) coefficients are reported in the following figures.
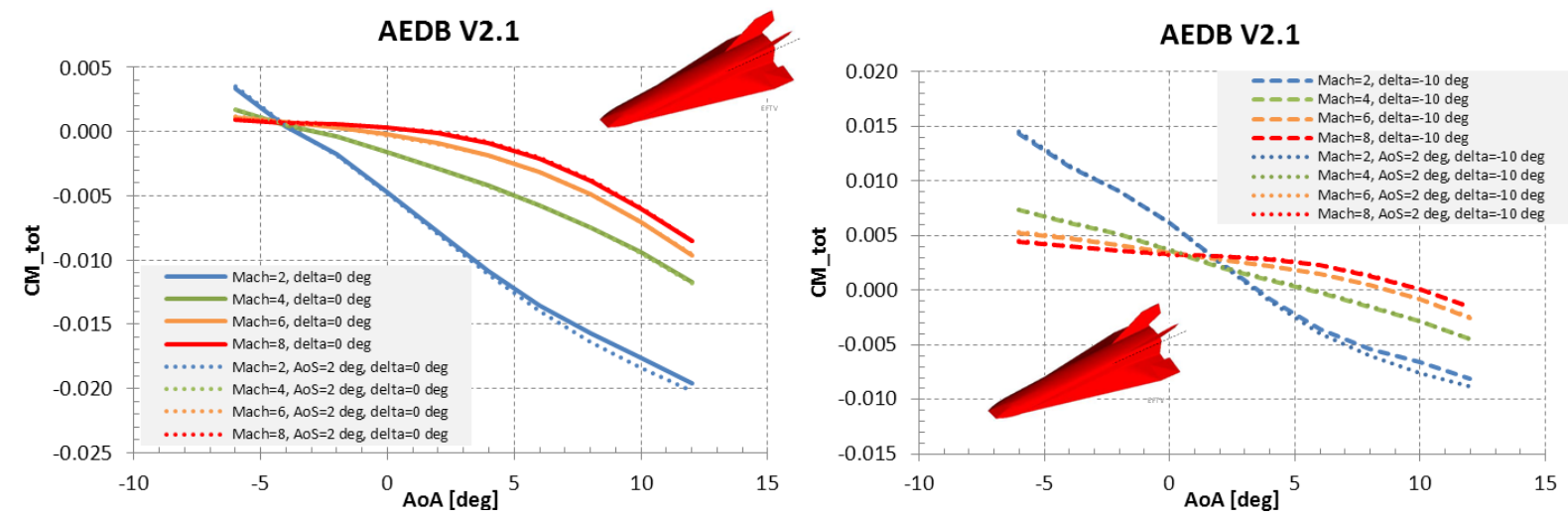

Figure 20. $C_{m}$ versus $A o A$ at different Mach numbers and with and without sideslip angle effects.
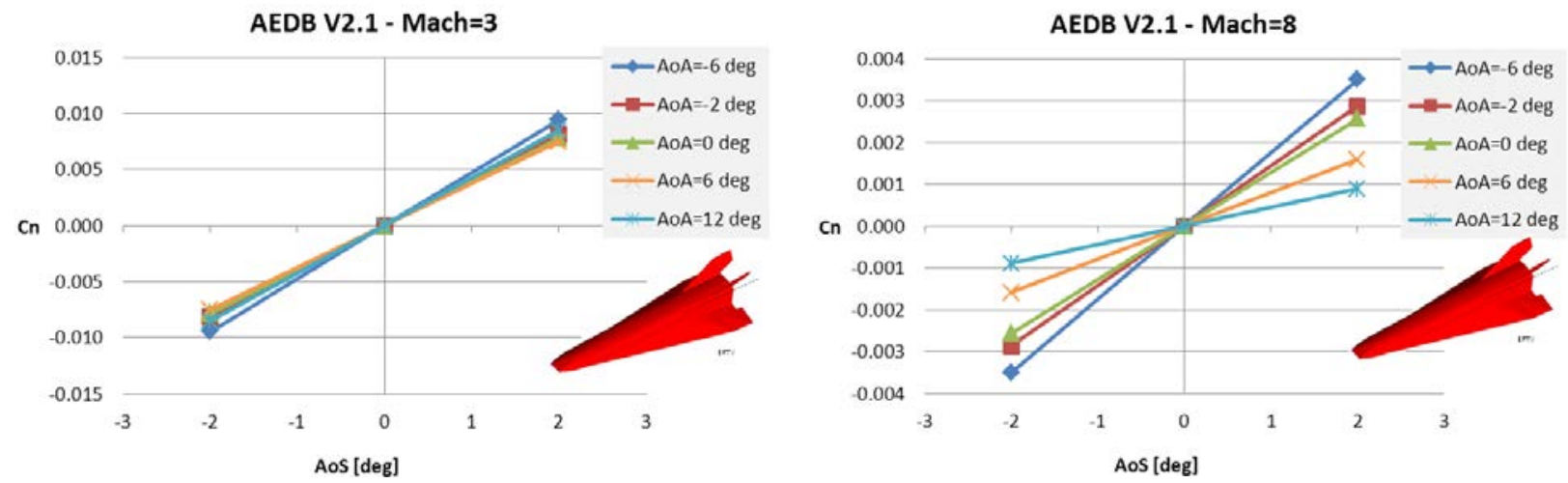

Figure 21. Cn vs. AoS at different AoA at Mach=3 (left) and Mach=8 (right).

15

American Institute of Aeronautics and Astronautics 


\section{Experimental Test Campaign}

In order to verify the preliminary AEDB and to define a proper uncertainty model to be used in the trajectory calculation, an experimental test campaign was carried on by TsAGI in the supersonic and hypersonic wind tunnel T-116, characterized by a test chamber with a squared cross section of $1 \mathrm{~m} \times 1 \mathrm{~m} \mathrm{size}^{14}$. The wind tunnel is a blow-down type exhausting into the atmosphere by the aid of ejectors. The working gas is air. It allows providing different types of tests with a Mach number range from 1.8 to 10. The duration of the runs is up to 7 minutes. To prevent condensation of the air components during test, the wind tunnel is equipped with electrical heaters. The total temperature ranges from 300 to $1075 \mathrm{~K}$.

Table 4 reports the complete matrix of experimental tests while Figure 22 shows the EFTV 0.35 scale model (1.15 m length), installed in the wind tunnel on a tail sting. Aerodynamic forces and moments acting on the model were measured by an electromechanical balance. The base drag was excluded from the experimental data by measuring the base pressure on the model and making corresponding correction. So, the resulting experimental data on aerodynamic coefficients correspond to the condition if the base pressure on the model equals to the free-stream static pressure. Corrections were made also for taking into account the effects of gravity and sting deformation during tests.

\begin{tabular}{|c|c|c|c|c|c|c|}
\hline $\mathbf{N}$ & Type of tests & $\mathbf{M}$ & AoA [deg] & AoS [deg] & $\begin{array}{c}\text { Aileron deflection } \\
\text { on pitch [deg] }\end{array}$ & $\begin{array}{c}\text { Asymmetric aileron } \\
\text { deflection [deg] }\end{array}$ \\
\hline $\mathbf{1}$ & Balance tests & $3,4,5,6,7,8$ & $-6 \div 12$ & 0 & 0 & 0 \\
\hline $\mathbf{2}$ & $\div$ & 4,7 & $-6 \div 12$ & 4 & 0 & 0 \\
\hline $\mathbf{3}$ & $\div$ & 4,7 & $-6 \div 12$ & 0 & $-18,-12,-6,6$ & 0 \\
\hline $\mathbf{4}$ & $\div$ & 4,7 & $-6 \div 12$ & 0 & 0 & $\delta_{\text {left }}=-12^{\circ}, \delta_{\text {right }}=12^{\circ}$ \\
\hline $\mathbf{5}$ & $\div$ & 7 & $-6 \div 12$ & 4 & 0 & $\delta_{\text {left }}=-6^{\circ}, \delta_{\text {right }}=6^{\circ}$ \\
\hline $\mathbf{6}$ & $\div$ & 7 & $-6 \div 12$ & 4 & 0 & $\delta_{\text {left }}=-18^{\circ}, \delta_{\text {right }}=6^{\circ}$ \\
\hline $\mathbf{7}$ & $\div$ & 5 & $-6 \div 12$ & 4 & 0 & $\delta_{\text {left }}=-6^{\circ}, \delta_{\text {right }}=12^{\circ}$ \\
\hline $\mathbf{8}$ & $\div$ & 5 & $-6 \div 12$ & 4 & 0 & $\delta_{\text {left }}=-6^{\circ}, \delta_{\text {right }}=-12^{\circ}$ \\
\hline
\end{tabular}

Table 4. Experimental tests performed at TsAGI.

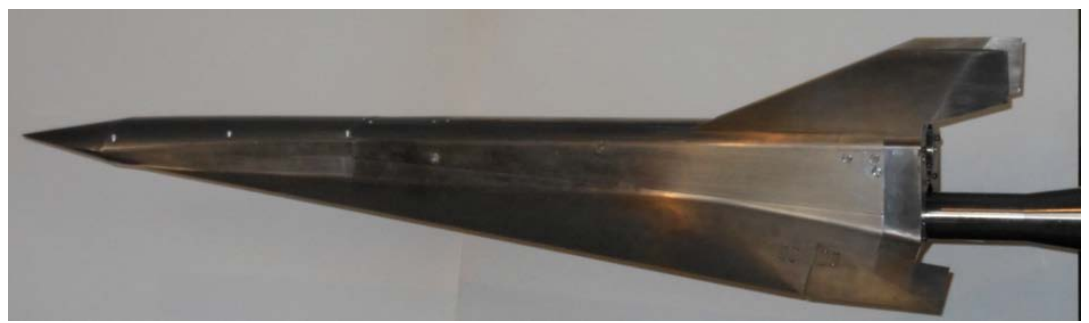

Figure 22. Glider model for TsAGI T-116 wind tunnel test campaign.

The free-stream flow parameters realized for the EFTV Glider model tests are reported in Table 5. Simulated flight altitudes (by Reynolds numbers, taking into account the scale of the model) correspond fairly well to the expecting flight test conditions.

\begin{tabular}{|c|c|c|c|c|c|c|}
\hline $\mathbf{M}$ & $\mathbf{3 . 0 3}$ & $\mathbf{4 . 0 5}$ & $\mathbf{5 . 0 5}$ & $\mathbf{6 . 0 0}$ & $\mathbf{6 . 9 9}$ & $\mathbf{7 . 8 8}$ \\
\hline $\mathbf{P}_{\text {tot, }}$ atm & 1.1 & 1.4 & 5.0 & 7.4 & 22.0 & 31.5 \\
\hline $\mathbf{T}_{\text {tot }} \mathbf{K}$ & 300 & 300 & 455 & 485 & 675 & 825 \\
\hline $\mathbf{R e}$ / $\mathbf{1 0}^{-6}$ & 7.74 & 5.96 & 6.88 & 6.32 & 7.66 & 5.92 \\
\hline \multicolumn{7}{|c|}{ Simulated Flight Altitudes: } \\
\hline $\mathbf{H}, \mathbf{k m}$ & 24.8 & 28.0 & 28.4 & 30.5 & 30.0 & 32.5 \\
\hline
\end{tabular}

Table 5. The flow parameters realized for Glider tests in T-116 wind tunnel.

16

American Institute of Aeronautics and Astronautics 
Aerodynamic characteristics of the EFTV Glider obtained from tests at different Mach numbers without sideslip angle and without aileron deflection are shown on Figure 23 in terms of drag force coefficient $C_{D}$, aerodynamic efficiency L/D, and pitching moment $\mathrm{C}_{\mathrm{m}}$ vs. angle-of-attack $\alpha$. The maximum values of the aerodynamic efficiency varying from 4.0 to 4.5 were achieved at $\mathrm{AoA}=2 \mathrm{deg}$. The pitching moment characteristics are very similar to those obtained by CFD.
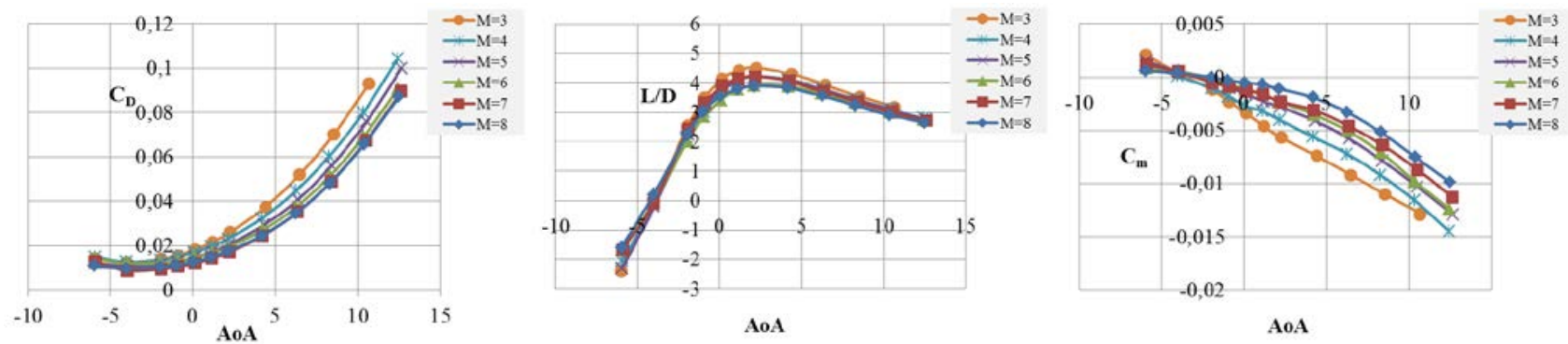

Figure 23. Experimental aerodynamic characteristics $C_{D}$ (left), $L / D$ (center) and $C_{m}$ (right) vs. AoA at different Mach numbers without sideslip angle, clean configuration.

Figure 24 represents the experimental data on pitching moment coefficient $\mathrm{C}_{\mathrm{m}}$ vs. symmetric aileron deflection $\delta$ at Mach numbers 4 and 7. According to these data, the EFTV glider can be trimmed at AoA range from -6 to +6 deg by aileron deflection from +2.5 to -16 deg at $M=4$, and from +4 to -12 deg at $M=7$.

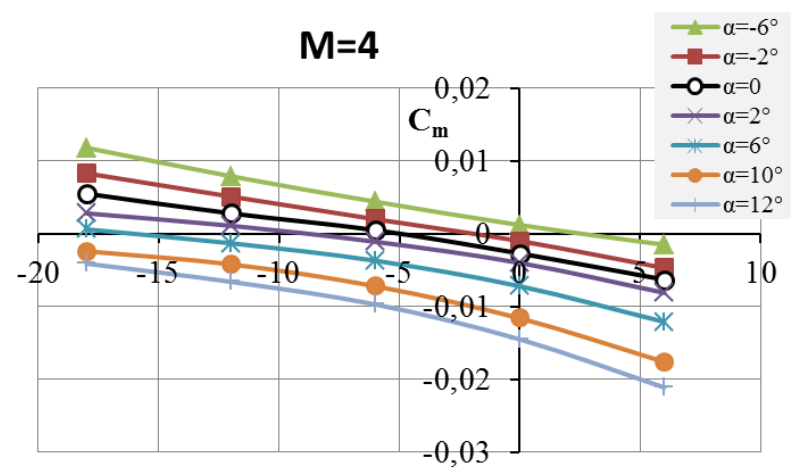

$\delta$

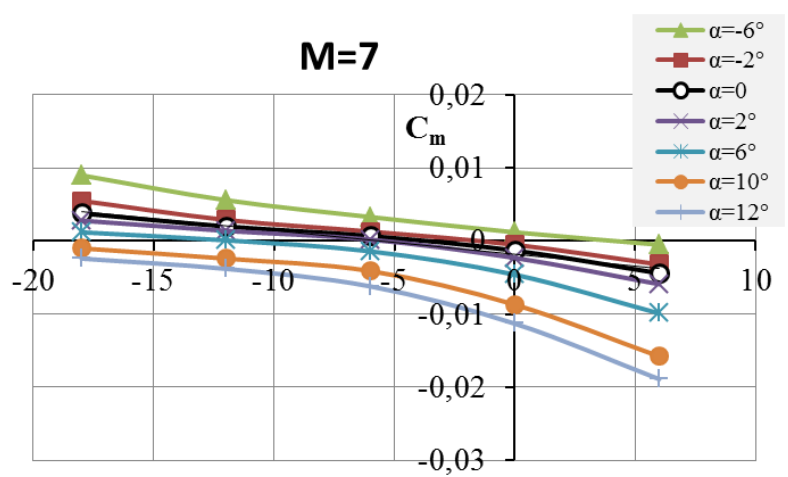

$\delta$

Figure 24. Pitching moment coefficient vs. elevon deflection angle without sideslip at $M=4$, and 7 and different AoA.

\section{The Aerodynamic Model of the EFTV Glider}

This section contains the EFTV Aerodynamic Model (AM) needed for the development of the vehicle aerodynamic database to be used for Flight Mechanics analysis, subsystem design and analyses, as well as for flight control analysis.

An important aspect of developing an aerodynamic database is the formulation of an aerodynamic model ${ }^{20}$. For example, the accuracy of the database depends on the degree to which the AM represents the physics of the problem. Therefore, it is important that all the aerodynamic and control variables that may have influence on the given aerodynamic coefficient must be included in the aerodynamic model.

To this end, a number of hypotheses have been assumed in developing the EFTV AM. Indeed, the independent variables that were recognized as influent on the EFTV aerodynamic state are: Mach number, M, Reynolds number, Re, angle of attack, $\alpha$, angle of sideslip, $\beta$, and aerodynamic surfaces deflection angles both as elevons, $\delta_{\mathrm{e}}$, and as ailerons, $\delta_{\mathrm{a}}$.

The couple (M, Re) identifies the aerodynamic environment while the remaining variables completely describe the flow field direction and vehicle state (i.e. configuration and attitude) ${ }^{20}$. Therefore, the functional structure of the AM of EFTV is based on these independent variables.

In particular, as typically done in a classical approach, each aerodynamic coefficient can be derived by supposing that each contribution to the single global coefficient is treated independently from the others. This means, from an operational point of view, that each aerodynamic coefficient is described by a linear summation over a certain number of incremental contributions. 
Each contribute is based on a small number of parameters, as recognized herein. Further, as done in the past for the US Orbiter and X-34 vehicles, the EFTV AM development relies on the following applicable assumptions ${ }^{21}$ :

1. Only rigid body aerodynamic coefficients are evaluated, i.e., no aero-elastic deformations are accounted for;

2. No Reynolds number effects on aerodynamic control surfaces are assumed;

3. No sideslip effects on aerodynamic control surfaces are assumed;

4. No effects of protrusions, gaps and roughness are considered;

5. No mutual aerodynamic interference between various control surfaces is considered.

\section{A. Development of Aerodynamic Database (AEDB_V2.0)}

The aerodynamic characteristics pertaining to the longitudinal and lateral degrees of freedom are presented as full scale rigid force and moment coefficients ${ }^{20}$. They are presented in a form allowing a build-up to any desired configuration and/or flight condition by incremental addition to the basic coefficient ${ }^{20}$.

Each aerodynamic coefficient was considered separately by the appropriate equation in which appear all the pertinent contributions for obtaining the total coefficient for any selected flight condition. Each element of the equation is defined and referenced. Indeed, following the formulation used for the Space Shuttle and assuming that the vehicle is operating at a combined AoA and AoS, the total lift coefficient is given by:

$$
C_{L, t o t a l}=C_{L, b}(\alpha, M)+\Delta C_{L, \delta_{e}}+\Delta C_{L, \delta_{a}}+\Delta C_{L, b, \beta}
$$

where $C_{L, \text { total }}$ is the total coefficient of the vehicle for a given flight condition as expressed by the flight Mach number $\mathrm{M}$, AoA $\alpha$, sideslip $\beta$, elevon deflection $\delta_{\mathrm{e}}$, and ailerons deflections $\delta_{\mathrm{a}}$.

The parameter $\mathrm{C}_{\mathrm{L}, \mathrm{b}}(\alpha, \mathrm{M})$ is baseline lift coefficient at zero sideslip and zero control surface deflections (i.e., in clean configuration). The parameter $\Delta \mathrm{C}_{\mathrm{L}, \delta_{\mathrm{e}}}$ represents incremental lift coefficient due to symmetric elevon deflections above the baseline, and it is given by:

$$
\Delta C_{L, \delta_{e}}=C_{L}\left(\alpha, M, \delta_{e}\right)-C_{L, b}(\alpha, M)
$$

The parameter $\Delta \mathrm{C}_{\mathrm{L}, \delta \mathrm{a}}$ represents the incremental lift coefficient due to aileron (asymmetric elevons) deflections above the baseline and can be evaluated using the data on symmetric elevons as follows:

$$
\Delta C_{L, \delta a}=\left(\frac{\Delta C_{L, \delta_{e}=\delta_{e}, L}+\Delta C_{L_{, \delta_{e}=\delta_{e}, R}}}{2}\right)-\Delta C_{L, \delta_{e}}
$$

Here, we use the elevon data twice, once assuming $\delta_{e}=\delta_{e, L}$, and obtaining $\Delta \mathrm{C}_{\mathrm{L}, \delta_{\mathrm{e}}=\delta_{\mathrm{e}}, \mathrm{L}}$, then assuming $\delta_{\mathrm{e}}=\delta_{\mathrm{e}, \mathrm{R}}$, and determining $\Delta \mathrm{C}_{\mathrm{L}, \delta_{\mathrm{e}}=\delta_{\mathrm{e}}, \mathrm{R}}$. As a check, when aileron deflection is zero, i.e., $\delta_{\mathrm{e}}=\delta_{\mathrm{e}, \mathrm{L}}=\delta_{\mathrm{e}, \mathrm{R}}$, the value of $\Delta \mathrm{C}_{\mathrm{L}, \delta_{\mathrm{a}}}$ vanishes as expected.

The incremental lift coefficient due to baseline (clean configuration) in sideslip are given by:

$$
\Delta C_{L, b, \beta}=C_{L}(\alpha, \beta, M)-C_{L}(\alpha, M)
$$

To get the incremental coefficient due only to sideslip $\beta$, we have to subtract the incremental due to AoA as shown by second term on the right hand side of equation. Those contributions represent aerodynamic cross coupling effects, and they have been found to be significant, especially at higher values of AoA.

In a similar fashion, we assume that the drag and pitching moment coefficients are given by:

$$
C_{D, \text { total }}=C_{D, b}(\alpha, M)+\Delta C_{D, \delta_{e}}+\Delta C_{D, \delta_{a}}+\Delta C_{D, b, \beta}+\Delta C_{D, b, \text { Viscous }}
$$




$$
C_{m, \text { total }}=C_{m, b}(\alpha, M)+\Delta C_{m, \delta_{e}}+\Delta C_{m, \delta_{a}}+\Delta C_{m, b, \beta}
$$

Viscous effects, included the term $\Delta C_{D, b, \text { Viscous }}$, have been then estimated by CIRA on the base of viscous CFD simulations ${ }^{13,14}$. Indeed, a viscous correction was added only to axial force, assuming a flat plate with a total wetted area of $7.35 \mathrm{~m}^{2}$. With this assumption, the skin-friction coefficient was evaluated by means of the modified Schlichting correlation ${ }^{22}$, to account for compressibility effects, i.e.

$$
C_{f}=\frac{0,42}{\left(\log _{10}\left(R e_{\text {Lref }}\right)\right)^{2,55}\left(1+0,25 M_{\infty}^{2}\right)^{0,31}}
$$

where $\infty$ stands for free-stream conditions.

The side force coefficient is assumed to be given by:

$$
C_{Y, \text { total }}=C_{Y, b}(\alpha, M)+\Delta C_{Y, \delta_{a}}+\Delta C_{Y, b, \beta}=\Delta C_{Y, \delta_{a}}+\Delta C_{Y, b, \beta}
$$

since the vehicle configuration is symmetric, i.e. $C_{Y, b}(\alpha, M)=0$.

Further,

$$
\Delta C_{Y, b, \beta}=C_{Y, b}(\alpha, \beta, M)-C_{Y, b}(\alpha, M)=C_{Y, b}(\alpha, \beta, M)
$$

Similarly,

$$
\Delta C_{Y, \delta_{a}}=C_{Y}\left(\alpha, M, \delta_{a}\right)
$$

Then,

$$
C_{Y, \text { total }}=C_{Y, b}(\alpha, \beta, M)+C_{Y}\left(\alpha, M, \delta_{a}\right)
$$

Proceeding in a similar way, the rolling and yawing moment coefficients are assumed to be given by:

$$
\begin{gathered}
C_{l, \text { total }}=C_{l, b}(\alpha, \beta, M)+C_{l}\left(\alpha, M, \delta_{a}\right) \\
C_{n, \text { total }}=C_{n, b}(\alpha, \beta, M)+C_{n}\left(\alpha, M, \delta_{a}\right)
\end{gathered}
$$

Therefore, it is assumed that the sideslip has effect only on the baseline, but it has no effect when elevons or ailerons are deflected. Moreover, no dependency on Reynolds number is assumed for the elevons/ailerons contribution. Indeed, even though this effect exists, it is however small and difficult to be modeled. Then, it has been considered as part of the aerodynamic coefficients uncertainty.

This model was implemented in a numerical tool, developed in Matlab ${ }^{\circledR}$, able to provide vehicle aerodynamic performance in points of the EFTV flight scenario where neither WT nor CFD data exist in a continuum fashion, thanks to its own polynomial formulation ${ }^{20,23}$.

\section{The Uncertainty Model for the EFTV Glider}

In order to use the Aerodynamic Database for the trajectory generation, a proper uncertainty model is required ${ }^{20,24}$. It is important to underline that the uncertainties must include two contributions: on one side the tolerances, that strictly depend on the accuracy of the numerical and physical modeling used for the computations and on the quality and accuracy of the 
experimental data; on the other side there are the so called variations, that depend on the estimated possible differences between nominal and real flight conditions and are mainly based on the experiences of previous flights ${ }^{20,24}$.

Within the design phase, it is important to take into account both terms, in order to design a more robust system and reliable control laws.

The generic coefficient $C_{i}$ is written as:

$$
C_{i}\left(\alpha, \beta, \delta_{r}, \delta_{l}\right)=C_{i_{n o m}} \pm \Delta C_{i, u n c}
$$

while the related uncertainty reads as follows:

$$
\Delta C_{i, u n c}=\Delta C_{i, b, u n c}+\Delta C_{i, \alpha, u n c} *\left(\alpha-\alpha_{R e f}\right)+\Delta C_{i, \beta, u n c} * \beta+\Delta C_{i, \delta_{e}, u n c} * \delta_{e}+\Delta C_{i, \delta_{a}, u n c} * \delta_{a}
$$

where

$$
\alpha_{R e f}=-4 \text { for } C_{L} \quad ; \quad \alpha_{R e f}=-6 \text { for } C_{m}
$$

Based on the comparison between the AEDB nominal values and the experimental data, and on available data on other hypersonic vehicles, a first set of uncertainties was defined. These values could be slightly modified in the next iterations with the flight mechanics. The uncertainties for each coefficient are reported in the following Table 6.

\begin{tabular}{|c|c|c|c|c|c|}
\hline & $\Delta C_{i, b \text {,unc }}$ & $\Delta C_{i, \alpha, \text { unc }}$ & $\Delta C_{i, \beta \text {, unc }}$ & $\Delta C_{i, \delta e, \text { unc }}$ & $\Delta C_{i, \delta a \text {,unc }}$ \\
\hline $\mathbf{C}_{\mathbf{L}}$ & 0.01 & 0.001 & & 0.0003 & \\
\hline $\mathbf{C}_{\mathbf{D}}$ & $0.0075^{*}$ & 0.001 & & & \\
\hline $\mathbf{C}_{\mathbf{Y}}$ & 0.0005 & & 0.001 & & 0.0002 \\
\hline $\mathbf{C}_{\mathbf{m}}$ & $0.002^{* *}$ & 0.0002 & & 0.0001 & 0.0001 \\
\hline $\mathbf{C}_{\mathbf{n}}$ & 0.001 & & 0.0002 & & 0.0003 \\
\hline $\mathbf{C}_{\mathbf{I}}$ & 0.002 & & 0.0003 & & 0.0002 \\
\hline
\end{tabular}

Table 6. Uncertainties for the aerodynamic database.

In the following figures, several comparisons between nominal AEDB coefficients and experimental data from TsAGI T116 wind tunnel test campaign are shown.

Uncertainties given by the model explained previously have been also reported in the figures.
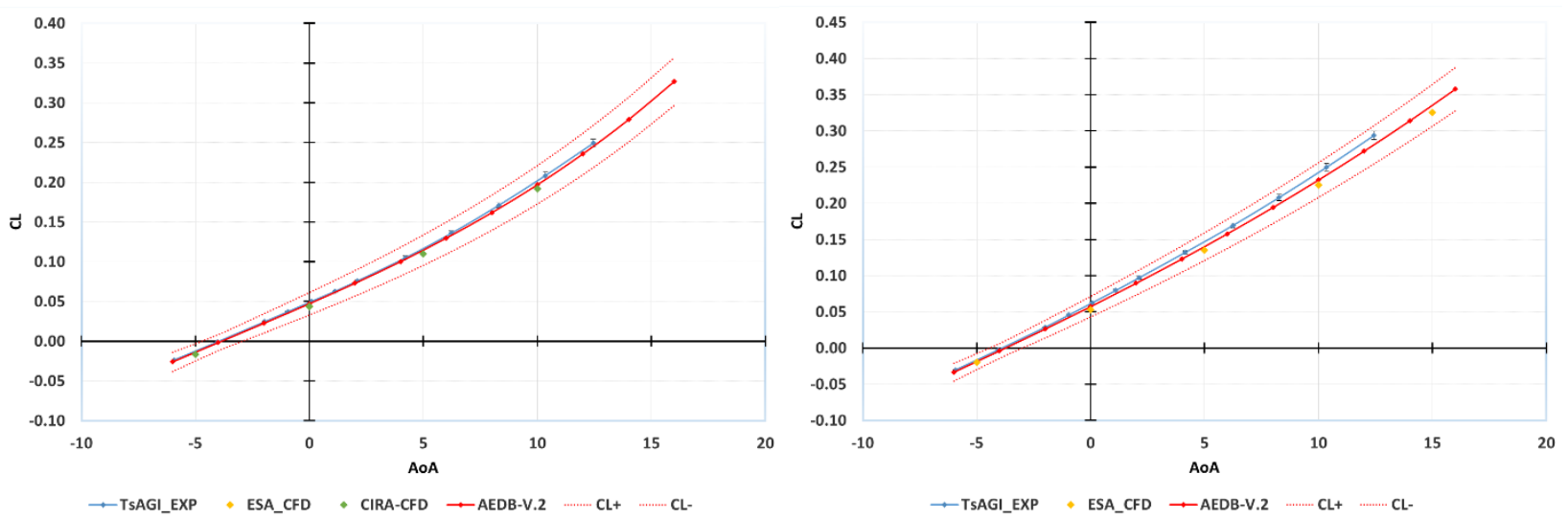

Figure 25. Comparison among AEDB, CFD, and WT data. Lift coefficient at $M=6$ (left) and $M=4$ (right), AoS=0 deg, clean configuration.

20

American Institute of Aeronautics and Astronautics 

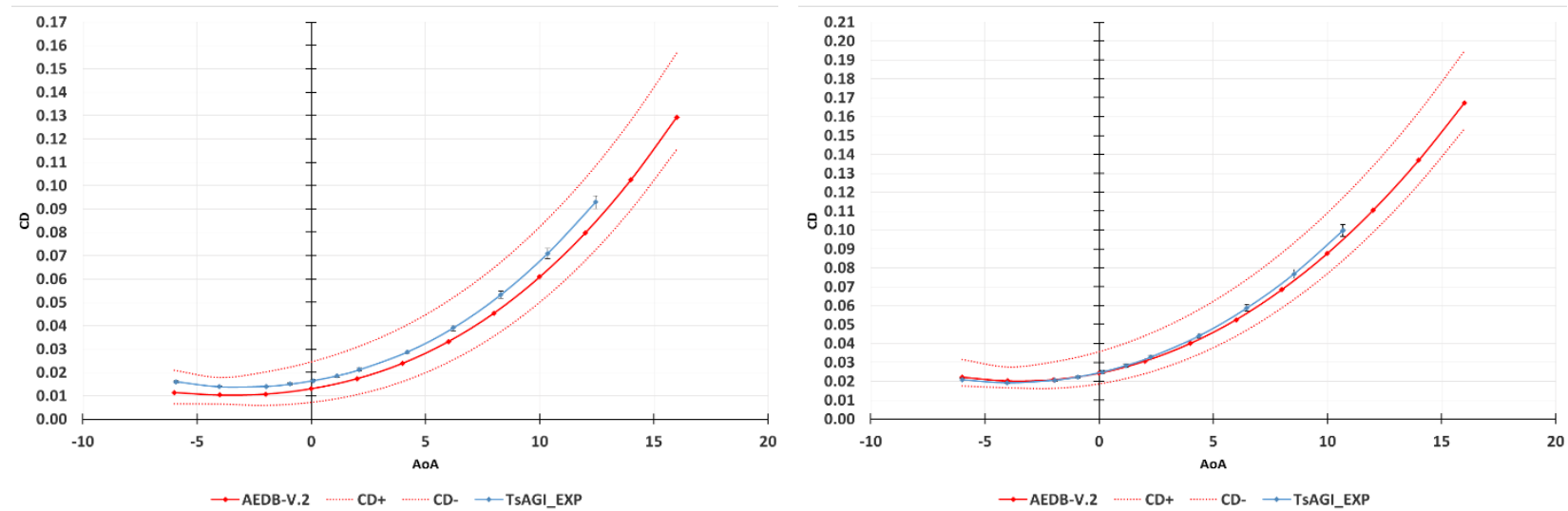

Figure 26. Comparison among AEDB, CFD, and WT data. Drag coefficient at $M=6$ (left) and $M=3$ (right), AoS=0 deg, clean configuration.
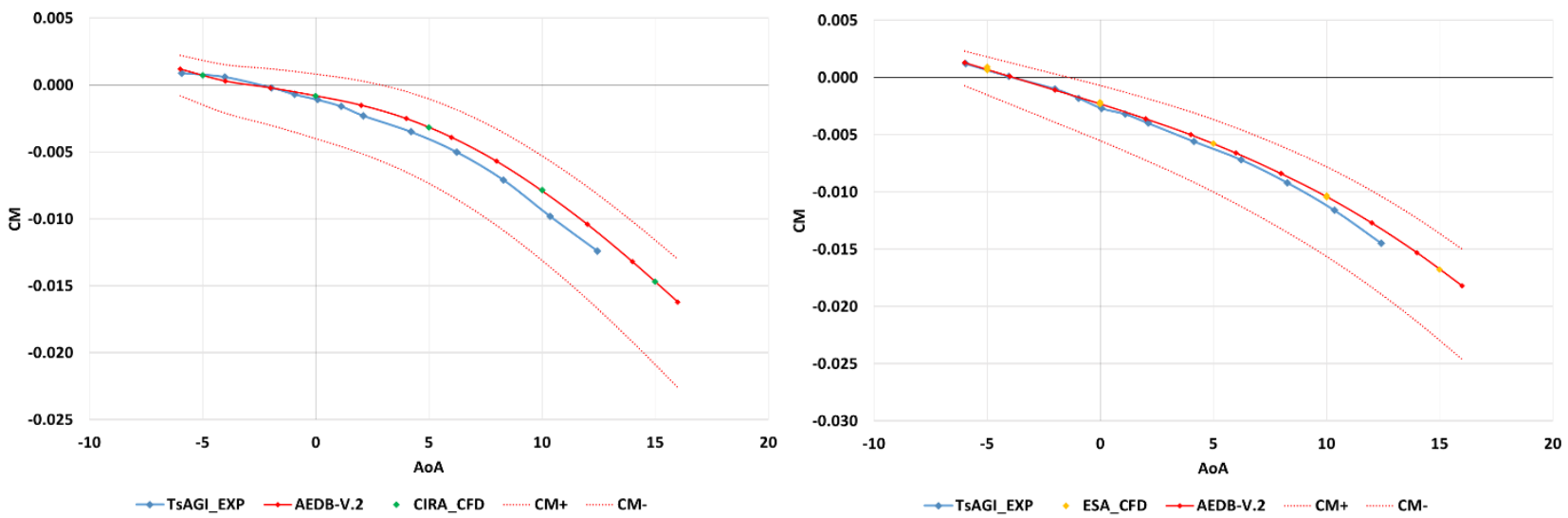

Figure 27. Comparison among AEDB, CFD and WT data. Pitching moment coefficient at $M=6$ (left) and $M=4$ (right), AoS=0 deg, clean configuration.
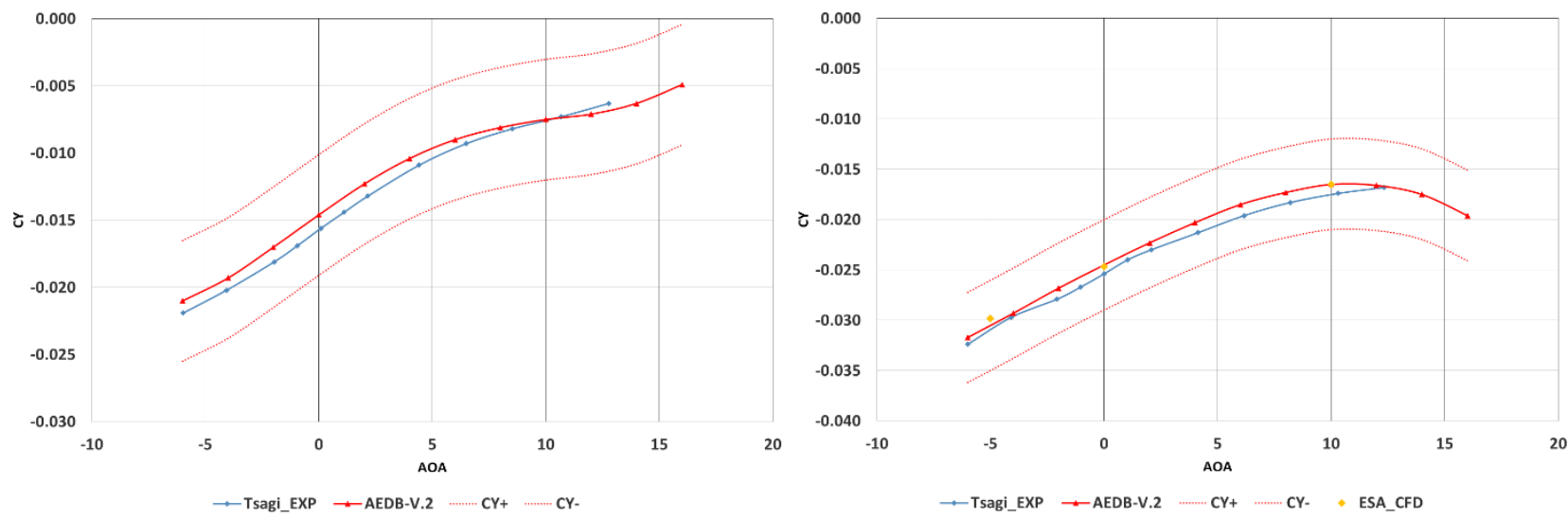

Figure 28. Comparison among AEDB, CFD, and WT data. Side force coefficient at $M=7$ (left) and $M=4$ (right), $\mathrm{AoS}=4 \mathrm{deg}$, clean configuration.

21

American Institute of Aeronautics and Astronautics 

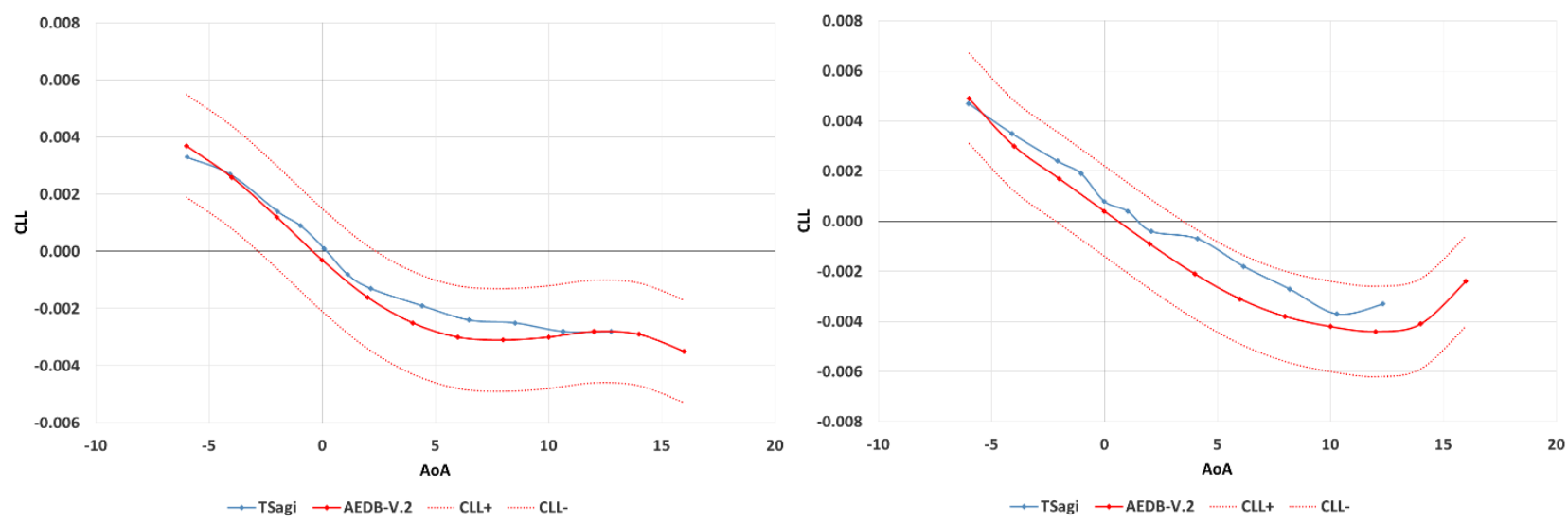

Figure 29. Comparison between AEDB and WT data. Rolling moment coefficient at $M=7$ (left) and $M=4$ (right), $\mathrm{AoS}=4 \mathrm{deg}$, clean configuration.
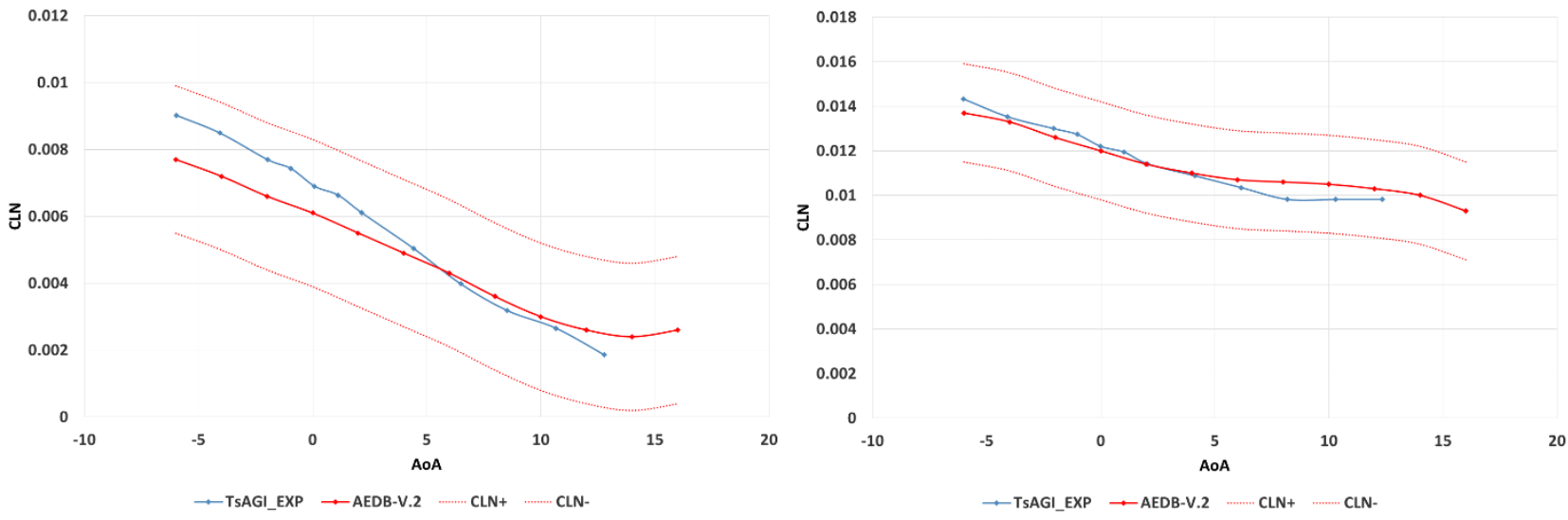

Figure 30. Comparison between AEDB and WT data. Yawing moment coefficient at $M=7$ (left) and $M=4$ (right), $\mathrm{AoS}=4 \mathrm{deg}$, clean configuration.
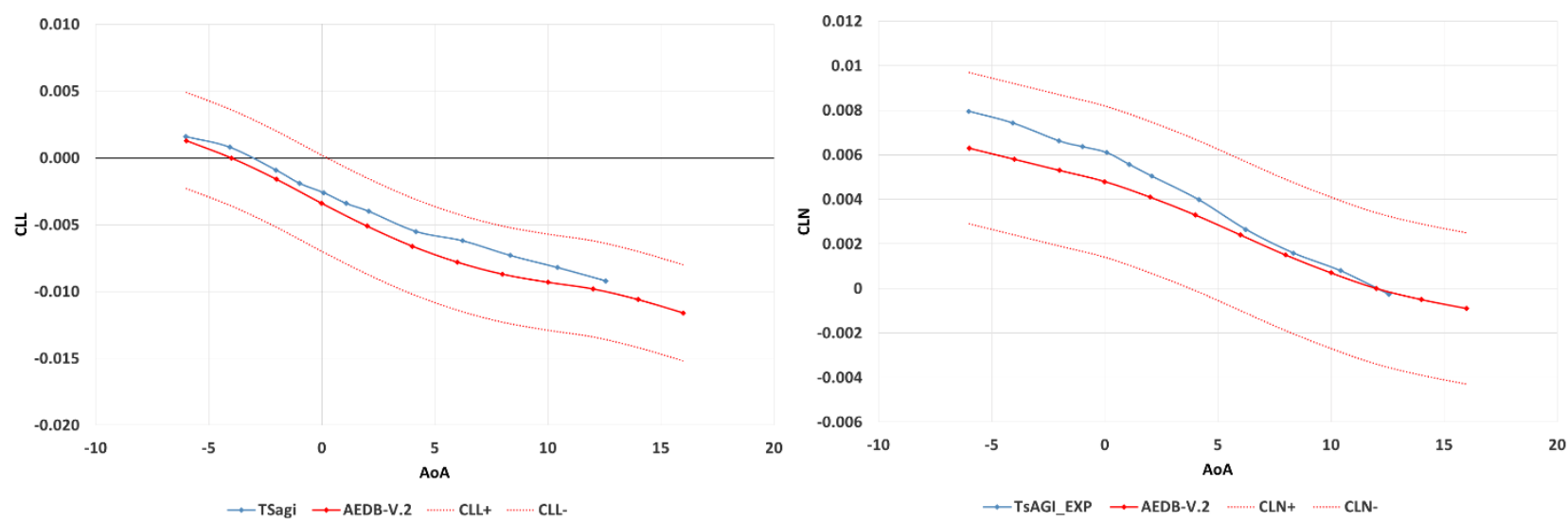

Figure 31. Comparison among AEDB, CFD, and WT data. Rolling moment coefficient (left) and yawing moment coefficient (right), $M=7$, AoS $=4$ deg, $\delta_{e, L}=-6$ deg, $\delta_{e, R}=6$ deg. 


\section{Concluding Remarks}

The present paper has dealt with the aerodynamic performance analysis of the experimental flight test vehicle under development in the seventh framework programme, namely HEXAFLY-INT. A mission scenario, the different flight segments and events to which the payload is exposed were described and justified. This allowed defining the aero-thermomechanical loads required to conceptually design all on board systems of the vehicle.

This flying test bed is a self-controlled glider configuration aiming to a levelled hypersonic flight at about Mach 8 and $30 \mathrm{~km}$ altitude, followed by a gliding descent combined with a banking manoeuvre up to the vehicle loss. During this flight, several experiments shall be carried out. The appraisal of the vehicle aerodynamic performance is needed for Flight Mechanics and Guidance, Navigation and Control analysis. In particular, hinge line moments for the glider aileron were also addressed to design the actuation lane and to select the actuator device itself. The vehicle design has made maximum use of databases, expertise, technologies and materials elaborated in previously European community co-funded projects ATLLAS I \& II, LAPCAT I \& II and HEXAFLY.

Numerical results have pointed out the compliance of vehicle's aerodynamic performance with the flight envelope expected for the glider.

Aerodynamic results highlighted that vehicle aeroshape features a lift-to-drag ratio greater than 4 for Mach ranging from 6 to 8 and angle of attack from - 1 to 7 deg. No significant effects of sideslip on aerodynamic efficiency, total pitching moment and map of trim-ability were predicted. Moreover, the glider is statically stable both in longitudinal and lateral-directional flight conditions with the provided moment reference point for positive angles of attack, and is trimmable in pitch in most of the flight conditions investigated in the present research effort.

An aerodynamic model for the glider, with related uncertainties, was built based upon a more populated aerodynamic database with viscous effects and results of TsAGI wind tunnel campaign at T-116 facility. This model plus uncertainties will serve Flight Mechanics for the calculation of the EFTV glider final trajectory with related dispersion and for the design of Flight Control System.

\section{Acknowledgements}

This work is performed within the 'High Speed Experimental Fly Vehicles - International' (HEXAFLY-INT) project fostering International Cooperation on Civil High-Speed Air Transport Research. HEXAFLY-INT, coordinated by ESAESTEC, is supported by the EU within the 7th Framework Program Theme 7 Transport, Contract no.: ACP3-GA-2014-620327. The project is also supported by the Ministry of Industry and Trade, Russian Federation. Further information on HEXAFLYINT can be found on http://www.esa.int/techresources/hexafly_int.

\section{References}

1. $\quad$ Favaloro, N., Pezzella, G., Carandente, V., Scigliano, R., Vitale, A., Rispoli, A., Steelant, J., "Design Analysis of the High-Speed Experimental Flight Test Vehicle HEXAFLY-International”, 20th AIAA International Space Planes and Hypersonic Systems and Technologies Conference, July Glasgow, Scotland. 2015. AIAA-2015-3607. doi: 10.2514/6.2015-3644.

2. $\quad$ Steelant, J., Langener, T., Di Matteo, F., Hannemann, K., Riehmer, J., Kuhn, M., Dittert, C., Scheuerpflug, F., Jung, W., Marini, M., Pezzella, G., Cicala, M., Serre, L., “Conceptual Design of the High-Speed Propelled Experimental Flight Test Vehicle HEXAFLY”, $20^{\text {th }}$ AIAA International Space Planes and Hypersonic Systems and Technologies Conference, Glasgow, Scotland, 6-9 July 2015: AIAA2015-3539.

3. $\quad$ Pezzella, G., Marini, M., Cicala, M., Vitale, A., Langener, T., Steelant, J., “Aerodynamic Characterization of HEXAFLY Scramjet Propelled Hypersonic Vehicle”, 32 ${ }^{\text {nd }}$ AIAA Aviation (Applied Aerodynamics Conference), 16-20 June 2014, Atlanta, GA: AIAA 20142844.

4. Steelant J., "European Activities on High-Speed Vehicles: Feasibility Studies and Technological Challenges for Hypersonic Cruisers”, $7^{\text {th }}$ European Symposium on Aerothermodynamics, ESA, ATD7-215019, May 2011, Bruges, Belgium.

5. Meerts, C., Steelant, J., “Air Intake Design for the Acceleration Propulsion Unit of the LAPCAT-MR2 Hypersonic Aircraft”, in $5^{\text {th }}$ European Conference for Aeronautics and Space Sciences (EUCASS), Munich, July 1-5, 2013.

6. $\quad$ Steelant, J., Varvill, R., Defoort, S., Hannemann, K. and Marini, M., “Achievements Obtained for Sustained Hypersonic Flight within the LAPCAT-II project”, 20th AIAA International Space Planes and Hypersonic Systems and Technologies Conference, July Glasgow, Scotland, UK, July 6-9, 2015: AIAA-2015-3677.

7. $\quad$ Scigliano, R., Pezzella, G., Marini, M., Di Benedetto, S., Steelant, J., “Aerothermal Design of the Hexafly-int Glider”. SPACE Conferences and Exposition, 13-16 September 2016, Long Beach, California, AIAA 2016-5627. DOI: 10.2514/6.2016-5627.

8. Steelant, J., Passaro, A., Fernandez-Villace, V., Gubanov, A. A., Ivanyushkin, D. S., Shvalev, Y. G., Voevodenko, N. V., Marini, M. and di Benedetto, S., "Boundary Layer Transition Assessment on a Slender High-Speed Vehicle”. 21 $1^{\text {st }}$ International Space Planes and Hypersonic Systems and Technology Conference, 6-9 March 2017, Xiamen, China. 
9. $\quad$ Steelant J., “ATLLAS: Aero-Thermal Loaded Material Investigations for High-Speed Vehicles”, $15^{\text {th }}$ AIAA International Space Planes and Hypersonic Systems and Technologies Conference, 28/04-01/05-2008, Dayton, Ohio, USA, AIAA-2008-2582.

10. Steelant J., “Achievements Obtained for Sustained Hypersonic Flight within the LAPCAT Project”. 15 ${ }^{\text {th }}$ AIAA International Space Planes and Hypersonic Systems and Technologies Conference, 28/04-01/05-2008, Dayton, Ohio, USA, AIAA-2008-2578.

11. Steelant J., "Achievements obtained on Aero-Thermal Loaded Materials for High-Speed Atmospheric Vehicles within ATLLAS”. $16^{\text {th }}$ AIAA/DLR/DGLR International Space Planes and Hypersonic Systems and Technologies Conference, October 19-22, 2009, Bremen, Germany, AIAA-2009-7225.

12. Steelant, J., Dalenbring, M., Kuhn, M., Bouchez, M. and von Wolfersdorf, J., “Achievements obtained within the ATLLAS-II Project on Aero-Thermal Loaded Material Investigations for High-Speed Vehicles”. $21^{\text {st }}$ International Space Planes and Hypersonic Systems and Technology Conference, 6-9 March 2017, Xiamen, China.

13. Bird, G. A., Molecular Gas Dynamics and the Direct Simulation of Gas Flows, Oxford Science Publications (1994).

14. Pezzella, G., Marini, M., Reimann, B., Steelant, J., “Aerodynamic Design Analysis of the Hexafly-INT Hypersonic Glider”, $20^{\text {th }}$ AIAA International Space Planes and Hypersonic Systems and Technologies Conference, Glasgow, Scotland, UK, 6-9 July 2015: AIAA2015-3644.

15. Steelant, J., Villace, V., Marini, M., Pezzella, G., Reimann, B., Chernyshev, S., Gubanov, A., Talyzin, V., Voevodenko, N., Kukshinov, N., Prokhorov, A., Neely, A., Kennell, C., Verstraete, D., Buttsworth, D., "Numerical and Experimental Research on Aerodynamics of High Speed Passenger Vehicle within the Hexafly-Int Project”. $30^{\text {th }}$ Congress of International Council of the Aeronautical Sciences, ICAS 2016, Paper no. 2016_0353. DDC Daejeon Korea. September 25-30, 2016.

16. Institute of Aerodynamics and Flow Technology, German Aerospace Center (DLR), The DLR TAU Code, 2012. url: http://tau.dlr.de/.

17. Spalart, P.R., Allmaras, S.R., “A One-Equation Turbulence Model for Aerodynamic Flows”, AIAA-92-0439, 1992.

18. Wada, Y., Liou, M.S., “A flux splitting scheme with high-resolution and robustness for discontinuities”, AIAA Paper 94-0083, 1994.

19. Anderson, W. Kyle, Bonhaus, Daryl L., “An Implicit Upwind Algorithm for Computing Turbulent Flows on Unstructured Grids”. Computers and Fluids, Vol. 23, No. 1, pp. 1-21, 1994.

20. Haselbacher, A., Blazek, J., “Accurate and Efficient Discretization of the Navier-Stokes Equations on Mixed Grids”, AIAA Journal, Vol. 38, No. 11, pp. 2094-2102, November 2000.

21. Pezzella, G., Marino, G., Rufolo, G. “Aerodynamic Database Development of the ESA Intermediate Experimental Vehicle”. Acta Astronautica, DOI:10.1016/j.actaastro.2013.07.019. Volume (94): Issue (1). January-February 2014. ISSN (0094-5765): pag. (57-72).

22. Pamadi, B. N., Brauckmann, G. J., Ruth, M. J., Fuhrmann, H. D., "Aerodynamic Characteristics, Database Development, and Flight Simulation of the X-34 Vehicle”. Journal of Spacecraft and Rockets, 2001 0022-4650 vol.38 no.3 (334-344) doi: 10.2514/2.3706.

23. Schlichting H. Boundary-layer Theory. New York, McGraw-Hill, 1955.

24. Viviani, A., Pezzella, G., “Aerodynamic and Aerothermodynamic Analysis of Space Mission Vehicles”. Springer International Publishing. DOI: 10.1007/978-3-319-13927-2. Hardcover ISBN 978-3-319-13926-5. eBook ISBN: 978-3-319-13927-2.

25. Cobleigh, B., R., “Development of the X-33 Aerodynamic Uncertainty Model”, NASA/TP-1998-206544, April 1998. 